\title{
Characterization of dendritic morphology and neurotransmitter phenotype of thoracic descending propriospinal neurons after complete spinal cord transection and GDNF treatment
}

Lingxiao Deng ${ }^{* 1,2}$, Yiwen Ruan*3 ${ }^{*}$, Chen Chen $^{2}$, Christian Corbin Frye ${ }^{2}$, Wenhui Xiong ${ }^{1}$

${ }^{2}$, Xiaoming Jin ${ }^{1,2}$, Kathryn Jones ${ }^{1,2}$, Dale Sengelaub ${ }^{4}$ and Xiao-Ming Xü ${ }^{\# 1,2}$

1. Department of Anatomy and Cell Biology, Indiana University School of Medicine, Indianapolis, IN 46202

2. Spinal Cord and Brain Injury Research Group, Stark Neurosciences Research Institute, Department of Neurological Surgery, Goodman and Campbell Brain and Spine, Indiana University School of Medicine, Indianapolis, Indiana 46202

3. Guangdong-Hong Kong-Macau Institute for CNS Regeneration (GHMICR), Jinan University, Guangzhou, China, 510632

4. Department of Psychological and Brain Sciences, Indiana University, Bloomington, IN 47405

*These two authors contributed to this work equally.

Running title: Propriospinal dendritic morphology after SCI and GDNF treatment

${ }^{\#}$ Correspondence should be addressed to:

Xiao-Ming Xu, Ph.D.

Spinal Cord and Brain Injury Research Group

Stark Neurosciences Research Institute

Indiana University School of Medicine

Neuroscience Research Building, 500E

320 West 15 th Street

Indianapolis, IN 46202-2266

Tel: 317-274-1036; E-mail: xu26@iupui.edu 


\section{ABSTRACT}

After spinal cord injury (SCI), poor regeneration of damaged axons of the central nervous system (CNS) causes limited functional recovery. This limited spontaneous functional recovery has been attributed, to a large extent, to the plasticity of propriospinal neurons, especially the descending propriospinal neurons (dPSNs). Compared with the supraspinal counterparts, dPSNs have displayed significantly greater regenerative capacity, which can be further enhanced by glial cell line-derived neurotrophic factor (GDNF). In the present study, we applied a G-mutated rabies virus (G-Rabies) co-expressing green fluorescence protein (GFP) to reveal Golgi-like dendritic morphology of dPSNs. We also investigated the neurotransmitters expressed by dPSNs after labeling with a retrograde tracer Fluoro-Gold (FG). dPSNs were examined in animals with sham injuries or complete spinal transections with or without GDNF treatment. Bilateral injections of GRabies and FG were made into the $2^{\text {nd }}$ lumbar (L2) spinal cord at 3 days prior to a spinal cord transection performed at the $11^{\text {th }}$ thoracic level (T11). The lesion gap was filled with Gelfoam containing either saline or GDNF in the injury groups. Four days post-injury, the rats were sacrificed for analysis. For those animals receiving G-rabies injection, the GFP signal in the T7-9 spinal cord was visualized via 2-photon microscopy. Dendritic morphology from stack images was traced and analyzed using a Neurolucida software. We found that dPSNs in sham injured animals had a predominantly dorsal-ventral distribution of dendrites. Transection injury resulted in alterations in the dendritic distribution with dorsal-ventral retraction and lateral-medial extension. Treatment with GDNF significantly increased the terminal dendritic length of dPSNs. The density of spine-like structures was increased after injury, and treatment with GDNF enhanced this 
effect. For the group receiving FG injections, immunohistochemistry for glutamate, choline acetyltransferase (ChAT), glycine, and GABA was performed in the T7-9 spinal cord. We show that the majority of FG retrogradely-labeled dPSNs were located in the Rexed Lamina VII. Over 90 percent of FG-labeled neurons were glutamatergic, with the other three neurotransmitters contributing less than 10 percent of the total. To our knowledge this is the first report describing the morphologic characteristics of dPSNs and their neurotransmitter expressions, as well as the dendritic response of dPSNs after transection injury and GDNF treatment.

Keywords: spinal cord injury; descending propriospinal neuron; dendrite; spine; rabies virus; GDNF 


\section{Introduction}

Over one hundred years ago it was recognized that a complicated intraspinal network of interneurons connecting spinal segments was present. Sir Charles Sherrington first described and named this unique population of spinal cord interneurons as propriospinal neurons (PNs) (Sherrington, 1885). Using electrophysiological techniques these neurons were later shown to play a critical role in motor reflexes, voluntary movement, and sensory processing (Alstermark et al., 2007; Gerasimenko et al., 2009; Jankowska, 1992). PNs have been shown to play a critical role in the relay of signals from supraspinal afferents such as the corticospinal (CST), rubrospinal (RST), tectospinal, and reticulospinal tracts to spinal motoneurons. PNs also receive input from muscle peripheral afferents, permitting feedback to muscle groups (Alstermark et al., 1984; Illert et al., 1978; Illert et al., 1977; Kostyuk and Vasilenko, 1978). This PN spinal circuitry allows for rapid correction of movement errors, while maintaining convergent supraspinal control and influence (Illert et al., 1978; Illert et al., 1977).

Descending propriospinal tracts (dPSTs) and their neurons (dPSNs) have recently been implicated in mediating plasticity under pathological conditions. Low thoracic axotomy invoked a strong regenerative response of descending thoracic propriospinal neurons to the injury (Siebert et al., 2010). Severed axons of commissural PNs can regenerate and make functional synaptic connections with spinal motoneurons (Fenrich and Rose, 2009; Siebert et al., 2010). dPSTs also responded to exogenous treatment with the neurotrophic factor GDNF and Schwann cells, resulting in successful regeneration through the lesion site (Deng et al., 2013; Iannotti et al., 2003; Xu et al., 1999; Zhang et al., 2009). Moreover, supraspinal axons, which usually fail to regenerate through and 
beyond the lesion site, form 'new' contacts with spared propriospinal neurons which project past a SCI lesion to lumbar segments (Bareyre et al., 2004; Courtine et al., 2008; Cowley et al., 2008; Nishimura et al., 2009; Vavrek et al., 2006). Therefore, reorganization of supraspinal-propriospinal relays may contribute to functional recovery after SCI.

Although the functional significance of the dPSNs has been emphasized for many years, the anatomical structure of these descending propriospinal neurons remains unclear. Previous morphological studies of these propriospinal neurons have largely relied on conventional dye tracing after electrophysiological recording (Ritz and Greenspan, 1985). Due to their scattered distribution within the spinal cord and diffuse projections, previous studies on dPSNs have been limited by the lack of a reproducible and efficient labeling method to identify PNs (Sterling and Kuypers, 1968). Another fundamental limitation was that conventional retrograde tracers used were primarily restricted to labeling the cellular somata, making the morphological study of the dendritic details of neurons impossible (Naumann et al., 2000). More recently, the use of retrogradely infectious viruses expressing genetically encoded fluorophores has been developed through which details of neuronal morphology can be clearly labeled without immunohistochemical amplification. Recombinant rabies virus has been widely used to reveal detailed neuronal morphology (Callaway, 2008; Collo et al., 2014; Ugolini, 2011; Weible et al., 2010; Wickersham et al., 2007). In this study, we used this recombinant rabies virus-based method to reveal the dendritic morphology of dPSNs that projected their axons from low thoracic spinal cord to the upper lumbar cord level in adult rats. Following a complete 
transection injury at the T11 spinal cord level, we also analyzed the effect of GDNF treatment on the dendritic plasticity of injured neurons.

\section{Materials and Methods}

\section{Animals}

Twenty-four Sprague Dawley adult female rats (180g-200g, Harlan) were used, twelve for the viral tracing study and the other twelve for the classification of neurotransmitter phenotype. Animals were divided into three groups, receiving either sham injuries or complete spinal transections with or without GDNF treatment. Experimental protocols were approved by the Institutional Animal Care and Use Committee (IACUC) of the Indiana University School of Medicine in accordance with the NIH Guidelines for the Care and Use of Laboratory Animals. All efforts were made to minimize the number of animals used and their suffering.

Viral and Fluoro-Gold $(F G)$ retrograde tracing

Rats were anesthetized by an intraperitoneal (IP) injection of a ketamine (40-95 $\mathrm{mg} / \mathrm{kg}) / x y l a z i n e(5-10 \mathrm{mg} / \mathrm{kg})$ cocktail. A laminectomy was performed to expose the $2^{\text {nd }}$ lumbar (L2) spinal cord. The dura was cut using a 26G needle to expose the spinal cord. Mutant monosynaptic rabies virus Rb-B19- $\Delta$ G-GFP (purchased from Salk Institute) was bilaterally injected into the intermediate gray matter (laminae V - VIII) of the L2 spinal cord $(0.75 \mu 1 /$ side, $10 \wedge 9 \mathrm{TU} / \mathrm{ml})$ using a stereotaxic apparatus. The virus was transformed into a first-order retrograde tracer instead of a trans-synaptic one (Wickersham et al., 2007). In our study, the dPSNs labeled by this G-mutated rabies virus include only those 
directly projecting to the intermediate zone of the L2 lumbar cord. The injection procedure lasted for 5 minutes including leaving the needle in place for 1 minute prior to retraction to limit leakage. For FG labeling, 2\% FG (Sigma 39286, Sigma-Aldrich, St. Louis, MO) was injected into the L2 spinal cord $(0.75 \mu 1 /$ side $)$ with the same stereotaxic parameters (Fig. 1).

\section{Spinal Transection}

Three days after viral or tracer injections, the animals in the experimental groups were anesthetized with ketamine/xylazine. A laminectomy was performed to expose the $11^{\text {th }}$ thoracic (T11) spinal cord. A pair of iridectomy scissors (Fine Scientific Tools, Foster City, CA) was used to transect the spinal cord. Successful transection was judged after exposure of the rostral and caudal stumps of the retracted spinal cords. Following transection, a probe was scraped along the inner wall of the vertebral canal through the lesion site to further ensure a complete spinal cord transection (Coulon et al., 2011). After bleeding in the lesion gap was stopped, gelfoam containing either 0.01M PBS or PBS containing GDNF $(3 \mu \mathrm{g} / \mu \mathrm{l}$ ) was placed into the lesion gap (Fig. 1). Sham animals received a laminectomy at the T11 level without spinal cord transection.

\section{Post-Operative Care}

Following each surgical procedure, the musculature was closed with 3.0 silk, and the skin was closed with 3.0 Nylon suture. External sutures were removed after the first week post-operatively. Buprenorphine hydrochloride (Buprenex injectable, 0.03 cc SQ, Ben Venue Laboratories Inc., Bedford, $\mathrm{OH}$ ) was given twice daily for the first 48 hours 
post-surgery. They also underwent bladder expression until sacrifice to prevent urinary tract infection.

Tissue processing, Imaging and $3 D$ reconstruction of viral labeled dPSNs

Four days after transection injury, animals were anesthetized using a ketamine/xylazine mixture and were perfused with cold PBS followed by 4\% paraformaldehyde. The whole spinal cord was carefully removed from the vertebral spine. Continuous sections of T6-T10 spinal cord segment were transversely sectioned at 150 $\mu \mathrm{m}$ thickness with a vibratome.

Labeled cells from all sections of the T6-10 cord segments were examined under a two-photon laser scanning microscope (Prairie Technologies, Middleton, WI) with 910 nm excitation light. Sections with completely labeled neurons were selected for further imaging. Stacks of images were collected by using a $20 \times$ water immersion lens and an increment of $1 \mu \mathrm{m}$. Initially, each stack of images was projected and saved as a .tif format; montage stack images of individual neurons were then created. The morphology of labeled cells in the stack images was reconstructed with Neurolucida (MBF Bioscience, Colchester, VT).

\section{Criteria for classification of dPSNs}

Our analysis was restricted to dPSNs from T6 to T10 spinal cord segments with axonal projections to the L2 spinal cord segment. Only those neurons whose somata were located in the intermediate gray matter (Rexed Lamina VII) were included. Each neuron was analyzed with respect to a coordinate system. The orientation of dendrites was 
defined as medial (close to the central canal), lateral (far from the central canal), ventral (close to the anterior horn), and dorsal (close to the posterior horn). Accordingly, the XYplane is the transverse plane of the spinal cord, the YZ-plan is the parasagittal plane, and the XZ-plane is the horizontal plane (Fig.2). Dendrites that could not be traced back to their soma were excluded. Neurons with incomplete dendritic trees were also excluded. Only neurons with labeled somata and more than $90 \%$ dendritic trees were considered complete cells and selected for final analysis.

\section{Quantitative morphometry}

Morphometric parameters were extracted with the Neurolucida analysis tool NeuroExplorer. To quantify the percentage of dendritic distribution in different orientations, we divided the spinal regions around each individual neuron into four quadrants and defined these quadrants as lateral $\left(320^{\circ} \sim 50^{\circ}\right)$, dorsal $\left(50^{\circ} \sim 140^{\circ}\right)$, medial $\left(140^{\circ} \sim 230^{\circ}\right)$ and ventral $\left(230^{\circ} \sim 320^{\circ}\right)$. The percentage of dendritic profiles appearing in these areas was calculated. To estimate the surface area of the three-dimensional cell bodies, the perimeter of each soma was first traced from its two-dimensional image. Then, by applying the formula for the surface area of an ellipsoid to the perimeter and two dimensional area measurements, the three-dimensional surface volume was calculated.

\section{Neurotransmitter immunohistochemistry}

To determine the transmitter phenotype of dPSNs, we performed experiments with FG retrograde labeling combined with immunohistochemistry. Four days after transection injury, animals received a lethal dose of ketamine/xylazine and were perfused transcardially with a fixation solution containing $4 \%$ paraformaldehyde and $0.3 \%$ 
glutaraldehyde in $0.1 \mathrm{M}$ phosphate buffer at $\mathrm{pH}$ 7.4. T7-9 spinal cords were removed from the spines and cryocut into $20-\mu \mathrm{m}$ thick transverse sections. We collected sections at every $100 \mu \mathrm{m}$ interval as a set for each neurotransmitter staining. Immunohistochemistry was performed using antibodies raised against protein-conjugated amino acid neurotransmitters (anti-glutamate, G9282, 1:10,000, Sigma-Aldrich; antiGABA, A2052, 1:5,000, Sigma-Aldrich; anti-glycine, 1:2,000, AB139, Chemicon, Temecula, CA; Millipore anti-Choline acetyltransferase, 1:100, AB144P, Chemicon) producing staining of distinct cellular populations. After incubating spinal cord sections with the primary antibody or antibodies for 48 hours, secondary antibodies matching the species of the primary antibody and labeled either with Cy3 (ab6939 Abcam MA) or Alexa Fluor 488 (A-11001 Life Technologies, NY) were employed to visualize their binding sites. To test the specificity of the primary antibody, they were omitted from control sections and no immunoreactivity was detected.

\section{Quantification of neuronal transmitter phenotype}

Patterns of staining were visualized under a fluorescence microscope using appropriate fluorescence filter sets. Counting of neuronal cell bodies was performed by a blind observer using Image $\mathbf{J}$ software. All results were based on four different animals on one set of sections per animal for each molecular marker and tracer. Counting fields were not allowed to approach the margins of the analyzed spinal cord regions to minimize inaccuracies due to edge effects that are likely to increase by difficult-todiscern cell types at their borders. Counting was done under high magnification objectives (20x). By focusing through the sections, marker and tracer co-localization was readily distinguished from stained elements at different depths. The numbers of cells 
stained for selected markers were counted and averaged for each combination of staining across all analyzed sections and experiments. Each set of section was stained for each different neurotransmitter. Neuron was selected only from intermediate grey matter. Quantitative analysis was based on the number of each section (n) through the caudalrostral extent of the analyzed. In each set, percentage of dPSN neurons with specific neurotransmitter $=$ the number of neurons co-labeled by FG and neurotransmitter antibody in this set /total number of neurons labeled by FG in this set.

\section{Statistical analysis}

All numerical data are presented as mean \pm SD. Statistical analysis was performed with GraphPad Prism version 5.0 (GraphPad, San Diego, CA). Due to the non-Gaussian distribution of morphology, the nonparametric Kruskal-Wallis test was used to determine the significance of group effect. One way ANOVA with Post hoc Tukey's test was performed to determine the effect of injury and GDNF treatment on other dendritic parameters. Two-way ANOVA was performed to determine the effect of either the factor of spinal cord level or the factor of injury/GDNF treatment (sham vs. injury vs. GDNF) independently or their possible interaction on neurotransmitter distribution. Post hoc Bonferroni's test was performed to compare means between groups. Significance was set at the $95 \%$ confidence interval.

\section{Results}


A total of 48 dPSNs were labeled by GFP fluorescence. The enhanced green fluorescent protein (EGFP) expressed by the virus filled all of the neuronal processes. The fluorescence intensity was high enough to label fine processes of dendrites. Forty-two labelled cells in the intermediate laminar were reconstructed. After careful examination of dendritic morphology, 36 cells met the criteria and were fully analyzed ( 15 cells in the sham group; 10 cells in the injury group; 11 cells in the injury + GDNF group).

\section{Orientation of dendritic distribution}

Labeled dPSNs were present bilaterally, and to maintain consistency in orientation, cells on the left side of the spinal cord were mirror-reflected. dPSNs displayed a variety of dendritic morphologies (Fig. 2). dPSNs extended their dendritic branches in medial, lateral, ventral, and dorsal directions (Fig. 2A), with some having a predominant dendritic distribution along the medial-lateral axis (Fig. 2B) or ventraldorsal axis (Fig. 2C). With NeuroExplorer, we analyzed the normal orientation of dendrites of dPSNs and their change after injury. dPSN neurons had relatively simple and sparse branches. To examine dendritic spatial orientation as a function of distance from the dendrite origin, polar histograms were constructed. The results from the polar histograms indicated a non-uniform distribution of dendritic profiles in sham animals and this overall distribution pattern changed after transection injury and GDNF treatment (data not shown). To further analyze the change within specific orientations, we divided the spinal regions around each individual neuron into four quadrants and defined these quadrants as lateral: $320^{\circ} \sim 50^{\circ}$; dorsal: $50^{\circ} \sim 140^{\circ}$; medial: $140^{\circ} \sim 230^{\circ}$; ventral: $230^{\circ} \sim 320^{\circ}$, and determined the percentage of the total dendritic length in each quadrant to reduce the variation (Fig. 3). This result showed that as a group, the dendritic distribution of 
intact dPSNs displayed a dorsal-ventral predominate distribution (lateral 13.78 $\pm 2.12 \%$, dorsal $35.75 \pm 3.70 \%$, medial $19.16 \pm 2.85 \%$, ventral $31.3 \pm 3.77 \%$; lateral versus dorsal $p<$ 0.001; lateral versus ventral $p<0.001$; dorsal versus medial $p<0.01$; medial versus ventral $p<0.05$ ) (Fig. 3C). After injury, the distribution changed to an unbiased pattern due to the retraction of dorsal and ventral dendritic profiles and extension of lateral and medial profiles (TX group: lateral $30.07 \pm 4.74 \%$, dorsal $19.75 \pm 4.23 \%$, medial $25.99 \pm 5.19 \%$, ventral $24.18 \pm 3.49 \% p>0.05$; TX+GDNF group: lateral $26.12 \pm 3.21 \%$, dorsal $20.97 \pm 2.19 \%$, medial $29.82 \pm 4.21 \%$, ventral $23.08 \pm 3.12 \% p>0.05$ ) (Fig. 3C). There was no significant difference in dendritic orientations between TX and TX+ GDNF groups.

Changes in dendritic length and dendritic branches after injury and GDNF treatment

With the data from NeuroExplorer, we analyzed parameters related to dendritic length and dendritic branches. Dendritic length included the total dendritic length (sum of all dendritic lengths), interval length (length between dendritic nodes) and terminal dendritic length, while parameters of dendritic branches included the number of total branches, interval nodes, and terminal branches. As shown in Fig. 4, the total dendritic length in the sham group was $2946.66 \pm 305.93 \mu \mathrm{m}$. It was increased to $3442.77 \pm 413.35$ $\mu \mathrm{m}$ after injury although it was not statistically significant $(p>0.05)$, and GDNF treatment enhanced this effect $(3951.73 \pm 340.53 \mu \mathrm{m}$, versus sham $p<0.05)$. The increase in total dendritic length may originate from the extension of individual dendrites, increased dendritic branches, or a combination of both. Increases in internal intervals and terminal length of dendrites would indicate increases in the extent of the dendritic arbor into the surrounding neuropil. Injury with or without GDNF treatment did not affect the 
portion of the dendritic arbor proximal to the soma, and there was no significant difference in internal intervals among the three groups $(p>0.05$, Fig. 4B). However, treatment with GDNF increased terminal length of DPSN dendrites of injured animals in a manner similar to that observed in total dendritic length, with terminal lengths of $2080.50 \pm 176.29 \mu \mathrm{m}$ in the sham group, $2563.84 \pm 257.13 \mu \mathrm{m}$ in the injury group (versus sham $p>0.05$ ), and $3101.83 \pm 269.67 \mu \mathrm{m}$ in GDNF-treated animals (versus sham $p<0.01$ ) (Fig. 4C). To examine the changes in dendritic number, we analyzed the number of dendritic branches, dendritic nodes (the points where dendrites bifurcate), and dendritic endings. Results showed that the number of total dendritic branches per cell was 16.39. \pm 1.72 in the sham group, $18.7 \pm 2.12$ in the injury group, and $20.36 \pm 1.47$ in the GDNF treatment group (Fig. 4E), and these did not differ across groups $(p>0.05)$. The number of dendritic nodes (sham, $6.33 \pm 0.81$; injury, $7.4 \pm 0.93$; and injury + GDNF, $7.55 \pm 0.56$ ) and dendritic endings (sham, $10.1 \pm 0.93$, injury, $11.3 \pm 1.22$, injury + GDNF, $12.3 \pm 0.89)$ also did not differ across groups $(p>0.05$, Fig. $4 \mathrm{~F} \& \mathrm{G})$. The number of dendritic terminal branches in sham, injury and injury + GDNF animals were 2.62 \pm 0.27 , $2.89 \pm 0.30$, and $2.84 \pm 0.24$ respectively $(p>0.05)$. The maximal order of a dendrite in sham, injury and injury + GDNF animals was $4.11 \pm 0.30,4.4 \pm 0.27$, and $4.45 \pm 031$ respectively $(p>0.05)$ (Fig. 4D \& H).

\section{Dendritic spine-like structures}

Because axotomy or GDNF treatment induced alterations of the dendritic arbors of neurons, this may have affected the distribution and density of spines as well. To investigate this, dendritic spine-like structures of neurons in the different groups were sorted and compared according to their occurrence on the dendrites. First, we found that 
dendritic spine-like structures of propriospinal neurons were distributed on all orders of dendrites but not in abundance. Five types of spine-like structures were found on dendrites and were classified as stubby, mushroom, regular (between mushroom and thin spines in morphology), thin, and filopodia (Fig. 5A). In sham animals, the average number of spine-like structures of each neuron was $23.88 \pm 2.15$ (Fig. 5B); the average density of spines of each neuron was $0.008 / \mu \mathrm{m} \pm 0.001$ (Fig. 5C). In sham animals the majority of spine-like structures were classified as stubby $(82.20 \% \pm 2.97)$, followed by regular $(9.73 \% \pm 2.39)$, mushroom $(6.25 \% \pm 2.34)$, thin $(2.89 \% \pm 1.35)$, and filopodia $(0.37 \% \pm 0.37 \%)$ (Fig. $5 \mathrm{C} \& \mathrm{E})$. After transection of the spinal cord, the total number of spine-like structures in each neuron significantly increased to $48.47 \pm 9.41$ (Fig. 5B, $p<$ 0.01 versus sham group), and to 3 fold the number in sham animals (74.72 \pm 12.38$)$ after GDNF treatment (Fig. 5B, $p<0.01$ versus sham group). The number of spine-like structures classified as stubby changed in the same pattern as that seen in the total number of spines, with $19.35 \pm 1.87$ in the sham group and increasing to $40.44 .0 \pm 8.46$ after transection of spinal cord (Fig. 5B, $p<0.01$ versus sham group), and to $64.09 \pm$ 9.30 in the GDNF treatment group (Fig. 5B, $p<0.01$ versus sham group). There were no significant changes in the numbers of the other types of spine-like structures among the sham, injury, and GDNF treatment groups (all $p>0.05$ versus sham group, Fig. 5B). The densities (number of spines / $\mu \mathrm{m}$ ) of the five types of spine-like structures changed in the same pattern as that seen in spine number in injury and GDNF treatment groups (Fig. 5C). The density of spine-like structures classified as stubby was $0.006 / \mu \mathrm{m} \pm 0.001$ in the sham group, increasing to $0.011 / \mu \mathrm{m} \pm 0.002$ after injury and to $0.015 / \mu \mathrm{m} \pm 0.002$ with GDNF treatment (Fig. 5C, $p<0.01$ versus sham group). The density of spine-like 
structures classified as filopodia was also significantly increased 8 fold between the sham and injury groups (Fig. 5C, $p<0.05$ versus sham group), but the number was still small in the injury group $(0.0003 / \mu \mathrm{m} \pm 0.0001)$. Interestingly, the proportion of all five types of spine-like structures remained consistent in all three groups (Fig. 5E).

In order to determine if there were different responses of spine-like structures to injury or GDNF treatment in different order of dendrites, we investigated the number of spines in each order of dendrites. The number of spines in each order showed a similar pattern in which more spines were found in GDNF-treated group (Fig. 5D). Increases in spines were significant in the first three orders of branches. In the first order, the number of spines was $5.00 \pm 1.24$ in the sham group. It slightly increased to $8.89 \pm 3.02$ after injury, and to $10.00 \pm 2.19$ when treated with GDNF ( $p<0.01$ versus sham group). In the second order, the number of spines dramatically increased from $5.00 \pm 1.24$ (sham group) to $19.89 \pm 3.30$ (injury group), and to $31.63 \pm 2.19$ (GDNF group) (all $p<0.01$ versus sham group). Changes in spine number in the third order were similar to that in the first order, with $5.14 \pm 1.39$ in the sham group and $9.11 \pm 4.82$ in injury group, but increased in the GDNF-treated group $(20.09 \pm 4.79, p<0.01$ versus sham group). The number of spines in the fourth and five orders were similar to that in the first order, and there were no significant differences across the groups (all $p>0.05$ versus sham group).

\section{Somata}

The somata of DPSNs were randomly distributed lateral to medial in lamina VII. There was a significant difference in somal volume among three groups: sham, $22156.57 \pm 4046.75 \mu \mathrm{m}^{3}$, injured, $31872.25 \pm 6854.58 \mu \mathrm{m}^{3}$, and GDNF-treated, $46602.29 \pm$ 
$8040.20 \mu \mathrm{m}^{3}$ ( $p<0.05$ sham versus GDNF-treated). The surface areas of the somata averaged 5196.00 $\pm 593.63 \mu \mathrm{m}^{2}$ in sham animals, $6401.38 \pm 1226.00 \mu \mathrm{m}^{2}$ in injured animals, and 7394.00 $\pm 949.23 \mu \mathrm{m}^{2}$ in GDNF-treated animals $(p>0.05)$. To determine the relative contributions of the dendrites and somata as sites of afferent input, the surface area of each soma was compared with the total dendritic area of each labeled dPSN. The somata accounted for a relatively small amount of the total dendrosomatic area of the cells, and there was no significant difference among the three groups (sham, 9.19 \pm 1.26 , injured, 10.01 \pm 2.05 , GDNF-treated, 7.45 $\pm 0.98 ; p>0.05)$.

\section{Neurotransmitter types}

In the thoracic segment, dPSNs labeled by FG were found mostly located in Rexed laminae VII. In order to characterize the neurotransmitter phenotypes of dPSNs, we employed glutamate and ChAT antibodies as markers for excitatory neurons and GABA and Glycine as markers for inhibitory neurons. Cells labeled by anti-glutamate, anti-GABA, anti-Glycine, and anti-ChAT were clearly distinguished from the fluorescent background by their intense labeling. FG (blue signal) labeled neurons quite consistently (Fig. 6). By merging the signals from the green, red, and blue channels, we could detect dPSNs with different neurotransmitters. Cell counts were performed at the T7 and T9 levels with 15 sections per segment ( $\mathrm{T} 7$ or $\mathrm{T} 9, \mathrm{n}=4$ /group). We found that the majority of the dPSNs in sham animals were glutamatergic neurons (T7: $92.75 \pm 2.4 \%$; glutamate + FG neurons/FG neurons $=1059 / 1142 ;$ T9: $90.49 \pm 1.5 \%$; glutamate + FG neurons $/ F G$ neurons $=1520 / 1680$ ). The other three types of neurons contributed less than 10 percent of the total dPSN population $(\mathrm{ChAT}$ T7: $5.1 \pm 1.2 \%$; ChAT + FG neurons/FG neurons $=$ 59/1162; T9: 5.51 $\pm 0.63 \%$; ChAT + FG neurons/FG neurons = 94/1709; GABA T7: 
$2.53 \pm 0.46 \% ; \mathrm{GABA}+\mathrm{FG}$ neurons/FG neurons $=28 / 1099 ; \mathrm{T} 9: 2.38 \pm 0.75 \% ; \mathrm{GABA}+$ FG neurons $/$ FG neurons $=37 / 1583 ;$ Glycine T7: $1.99 \pm 0.32 \%$; Glycine + FG neurons $/$ FG neurons $=24 / 1244 ;$ T9: 2.33 $\pm 1.04 \% ;$ Glycine + FG neurons/FG neurons $=37 / 1605)($ Fig. 7A). Transection injury caused significant reductions in the number of FG-labeled neurons in the rostral spinal cord proximal to the injury (sham T7: $523.1 \pm 10.42$, T9: 775.06 \pm 47.80 ; injury T7: 420.70 \pm 91.74 , T9: 393 \pm 37.98 ; injury + GDNF: T7: 400.23 $\pm 41.56, \mathrm{~T} 9: 332.19 \pm 25.72 ; p<0.001$, sham versus injury, $p<0.001$, sham versus injury + GDNF) (Fig. 7B). The reduction of FG-labeled neurons in these rostral segments was likely due to axotomy-induced dPSN cell death, and GDNF treatment did not reverse such death.

\section{Discussion}

A neuron's morphology, especially the dendritic arbor, represents one of the most important distinguishing features of neuronal type and often accounts for a neuron's physiological role in a circuit (Markram et al., 2004). Neurons are driven by the code of synaptic inputs to conduct their physiological function (Kuhn et al., 2004). Several dendritic characteristics, including branching patterns, size, and orientation of dendritic trees determine how synaptic inputs are integrated (Cline, 2001; Henze et al., 1996). dPSN dendritic morphology have not been described previously. Identification of morphological properties of normal and injured dPSNs can provide fundamental knowledge of this group of neurons and elucidate the mechanisms of their contribution to the functional recovery after SCI. The complicated physiological roles of the dPSN 
system indicate their complex compositions which can be reflected by their diverse targeted neurons (Flynn et al., 2011). Thoracic intraspinal projections arising from the intermediate zone have been found to be directed to spinal motoneurons and to nonmotoneuron elements in the intermediate zone where central pattern generators (CPGs) are mainly located (Alstermark and Isa, 2002; Ballion et al., 2001; Gerasimenko et al., 2009). Therefore, dPSNs not only directly control the limb movement but also facilitate forelimb/hindlimb coordination through CPGs during natural stepping (Gerasimenko et al., 2009). Ni (2014) used a recombinant rabies virus-based method to trace a subset of the long descending propriospinal neurons that form monosynaptic connections directly with motor neurons of the hindlimb (Collo et al., 2014). Our study focused on another subgroup of dPSNs which project to the intermediate zone of the lumbar enlargement that likely make contact with either dendrites of motoneurons or non-motoneuron elements including those contributing to lumbar CPG (Guevremont et al., 2006; Sterling and Kuypers, 1968).

\section{Dendritic morphology of DPSNs}

Rodents lack direct connections from cortex to spinal motoneurons. Instead, interneuron circuits, especially the descending propriospinal system, relay supraspinal commands. Working in concert with supraspinal neurons, the descending propriospinal neurons residing in Lamina VII integrate both motor and sensory inputs and therefore finely tune locomotion, limb coordination, and postural support (Delwaide et al., 1977; Miller et al., 1973; Skinner et al., 1980). Most of the dorsal CST has been found to terminate its axons in the intermediate zone (Rosenzweig et al., 2009). The "ventral intermediate zone" has also been found to be the chief area of termination of tectospinal 
fibers (Nyberg-Hansen, 1964, 1965). In addition, spinal interneurons are connected with sensory afferents such as dorsal root fibers which penetrate the dorsal funiculus and traverse the dorsal horn (Ritz and Greenspan, 1985). This connection conveys feed forward information from sensory to motoneurons (Cote et al., 2012). Thus, major signals transduced through dPSNs come from afferent projections located both dorsally and ventrally relative to the dPSNs, which may account for the predominant dorsal-ventral dendritic distribution in the transverse plane of normal dPSNs found in our study. In cats and other mammals, Golgi stained neurons in the ventromedial, lateral, and central areas of lamina VII display a predominant dorsoventral dendritic orientation. The dendritic distributions were extensive in the transverse plane but were restricted rostrocaudally (Berkowitz et al., 2006; Brown, 1983; Scheibel and Scheibel, 1969). Therefore, we believe that this dendritic distribution pattern of dPSNs may be conserved across the species (Fetcho, 1992; Kusuma and ten Donkelaar, 1979; Nieuwenhuys, 1964). The dPSNs in lamina VII had only a few dendrites, which for the most part did not have complicated branches. These dendrites extended dorsally into lamina $\mathrm{V}$ and ventrally into lamina IX where the ventral horn motoneurons were located. Such dendritic orientation of dPSNs is in sharp contrast to the longitudinal dendritic orientation of other intraspinal neurons such as the GABAergic islet interneurons in the dorsal horn as well as to the pronounced longitudinal dendritic bundles of the motoneurons (Fargo and Sengelaub, 2007; Maxwell et al., 2007; Sengelaub and Forger, 2008). The different dendritic patterns may reflect the functional variety of different intraspinal neurons.

Dendritic plasticity induced by axotomy 
The changes in dendritic morphology of neurons after ischemia/hypoxia have been reported by other investigators. For example, after neuronal damage there is an acute reduction in apical and basal dendritic number in hippocampal neurons (Biernaskie and Corbett, 2001; Pokorny and Trojan, 1983; Pokorny et al., 1982). In contrast, Ruan (2006) reported that the dendrites of CA1 neurons undergo disorientation and an increase in apical dendritic length shortly after transient cerebral ischemia (Ruan et al., 2006). Interestingly, we also found an outgrowth in distally axotomized DPSN dendrites, especially in the terminal dendritic branches. More importantly, as a group, the dendritic distribution pattern changed from a predominantly dorsal-ventral distribution to an unbiased distribution due to the dorsoventral retraction and lateromedial extension of the dendrites.

Several mechanisms might be involved in the axotomy-induced dendritic plasticity. Firstly, immediate post-injury dendritic outgrowth may be due to an excessive activation of glutamate receptors after injury. Activation of NMDA receptors stimulates dendritic outgrowth by increasing intracellular calcium (Cambray-Deakin and Burgoyne, 1992; Ciccolini et al., 2003; Hirai and Launey, 2000). Secondly, since the dPSN system is a point of convergence for various peripheral inputs, deafferentation caused by transection SCI can cause rapid dendritic atrophy of central neurons (Horch et al., 2011). Thirdly, the dendritic plasticity could reflect a compensatory response of the spinal cord to the functional deficits caused by the insult.

Although the adult mammalian CNS has only limited capacity for axonal regeneration upon injury, there is high capacity for short-distance rearrangement, redistribution and reconnection of axons and synaptic rewiring to repair and compensate 
for the loss of function. The extent of functional recovery depends on the efficiency of neural circuit reconnection. The dPST has been found to be important in relaying the supraspinal signal. Their dendritic distribution therefore needs to be aligned with distribution of supraspinal terminals. In rodents and primates, the corticospinal tract (CST) axons project mainly to the intermediate gray matter (Bareyre et al., 2004; Rosenzweig et al., 2010) where dPSNs are located. The compensatory plasticity could also occur between the reticulospinal tract (ReST) and dPSNs. For example, the ReST axons from the intact hemicord could cross the spinal midline in response to the injury (Filli et al., 2014). Therefore, the dendritic orientation and plasticity of dPSNs observed in the present study provides an anatomical basis for a compensatory mechanism of dPSNs relaying the supraspinal signal. In addition to relaying the supraspinal signal, dPSNs also play an important role in mediating sensory input in facilitating functional recovery such as reactivating and reorganizing the intraspinal locomotor (Barbeau and Rossignol, 1987). Since the sensory input mainly comes from the dorsal spinal cord, an attractive strategy is to promote dorsal dendritic extension of dPSNs (Fouad et al., 2001).

In the present study, we studied dPSN dendritic morphology and plasticity mainly at the acute stage of SCI. Knowledge related to such acute changes may be beneficial for the development of strategies targeting early neuronal and dendritic degenerations after injury. We chose 7 days post-injury as a major time point for observing dendritic plasticity. This time point is very critical, as injured neurons can either undergo injuryinduced degeneration or initiate regenerative responses (Deng et al., 2014; Donnelly and Popovich, 2008; Siebert et al., 2010). 
Although local increases of endogenous GDNF protein may not be sufficient for nerve regeneration and locomotor improvement, it may support neuronal survival. Exogenous application of neurotrophic factors can further prevent atrophy of axotomized neurons and increase the intrinsic capacity of mature neurons to regrow axons (Bregman et al., 1998; Coumans et al., 2001). The usage of GDNF in our study was based on observations that GDNF supports survival and regeneration of descending propriospinal neurons in adult and neonatal rats after SCI (Baumgartner and Shine, 1998; Deng et al., 2013; Dolbeare and Houle, 2003; Henderson et al., 1994; Li et al., 1995; Oppenheim et al., 1995; Watabe et al., 2000). The expression of GDNF receptors, such as the ligandbinding component (GFR-1) and the transmembrane Ret receptor tyrosine kinase (Trk) cRET in descending propriospinal neurons, is upregulated after SCI (Airaksinen et al., 1999; Kokaia et al., 1999; Siebert et al., 2010). Notably, rabies virus selectively infects neurons with neurotrophin receptor (p75NTR) and GDNF receptor NCAM (Sissoeff et al., 2005). NCAM and p75NTR both can mediate the neuroprotective effect of GDNF (Barati et al., 2006; Zhou et al., 2003). The direct actions of GDNF on the pattern of dendritic arborization in developing neurons and injured neurons via a target-derived retrograde transport mechanism has been reported, and axonal injury can enhance the transport rate (Kashiba and Senba, 1999; Neet and Campenot, 2001; Vrieseling and Arber, 2006). GDNF treatment is associated with up regulation of II-tubulin or GAP-43 mRNA (Storer et al., 2003; Vrieseling and Arber, 2006). However, the GDNF effect on dPSN dendritic plasticity is still not optimal. Several possibilities may account for the less optimal effect of the GDNF. First, GDNF used for this study was recombinant proteins that might have quickly degraded after being administered into the lesion site. Second, the treatment 
lasted for only 4 days, which may be too short to exert an optimal effect. Last, the dose of GDNF may not be sufficient to exert a strong effect. Without long term application of high concentrations of GDNF, it is not surprising to see some, but not dramatic, effect of GDNF on dendritic plasticity although GDNF clearly shows an effect on several critical parameters of dPSN dendrites (e.g. Fig. 4).

Plasticity of dendritic spine-like structures induced by axotomy

There is a large amount of evidence demonstrating that dendritic spines can change shape, size, and number following various injuries or disease insults (Fiala et al., 2002; Halpain et al., 2005; Tan and Waxman, 2012). Injured glia release their internal stores of glutamate into the environment, which can activate AMPA and NMDA receptors. The downstream signals such as CaMKII, PKC, PKA, MAPK, and Rac1 regulate dendritic spine morphology through actin cytoskeleton reorganization (Tan and Waxman, 2012). The function of these receptors can be enhanced by accumulation of endogenous neurotrophins, such as brain derived neurotrophic factor (BDNF), GDNF, and neurotrophin-3 (NT-3), in the environment after SCI. The number of spines may increase when inputs that contribute to the suppression of synapses are lesioned. The increased number of available axonal inputs may also lead to more spines. The remaining dendrites after injury may express more spines to compensate for the overall loss of afferents input (Ferrer et al., 1988; Sunanda et al., 1995). The dendritic spine remodeling induced by injury is similar to activity-dependent synaptic plasticity in models of learning and memory (Tan and Waxman, 2012). Increased dendritic spine density is observed in neurons that have entered into a more plastic state, indicating availability to form new or stronger synapses (Alvarez and Sabatini, 2007). Similar to stalked (Gobel, 1975), dPSNs 
in our study with similar dendritic patterns possessed only a few spine-like structures. After injury and treatment with GDNF, we found increases in the density of spine-like structures which could indicate a more plastic state induced by injury and GDNF therapy. The plasticity in spine-like structures appeared in several orders of dendrites, and with spine-like structures classified as stubby and filopodia mainly contributing to this change. Compared to regular spines, stubby and filopodia spines are considered to be more dynamic, unstable, and immature (Yuste and Bonhoeffer, 2004). Following contusive SCI, increases in dendritic spine length and spine head diameters were observed 1-month post-injury. The change of synaptic density happened mainly in dendritic regions closer to the soma and occurred for all spine types, with a particularly marked redistribution occurring with mushroom spines (Zuo et al., 2005). The differences between our findings and those of Zuo et al. (2005) may be due to the different time periods during which the spines were assessed.

\section{Neurotransmitter phenotypes of dPSNs}

A major challenge for understanding how locomotor patterns are generated is in determining the intraspinal organization of chemically characterized groups of neurons that converge on different motoneuron pools. dPSNs play an essential role in coordinating rhythmic motor activity between the forelimb and hindlimb during locomotion. From physiological studies in mammals it is known that this coordination involves glycinergic, GABAergic, glutamatergic, and cholinergic spinal cord interneurons (Juvin et al., 2005; Mahmood et al., 2009). Other spinal interneurons, such as CPG neurons and premotor interneurons, have been characterized by neurotransmitter phenotype (Collo et al., 2014; Coulon et al., 2011). Little is known about 
neurotransmitter phenotype of dPSNs, and our study, for the first time, describes the relative proportions of putative glycinergic, GABAergic, cholinergic, and glutamatergic dPSNs in the laminae VII of the mid-low thoracic spinal cord. Our results indicate that the majority of FG-labeled dPSN neurons are glutamatergic neurons. This proportion is much higher than that of other premotor neurons (Collo et al., 2014). Therefore, the dPSNs may represent a unique population of propriospinal neurons. In the current study, after spinal transection, many dPSNs died in the segment proximal to the injury. However, the relative proportions of the different neurotransmitters present in dPSNs did not change. The response of dPSNs to the injury therefore mainly depended on the distance of soma from the injury but not the neurotransmitter phenotype (Siebert et al., 2010). Interestingly, previous literature has provided some clues that link dendritic morphology to specific neurotransmitter phenotypes. Most GABAergic interneurons in the dorsal horn, defined as islet cells or central cells, also have a rostral-caudal distribution of their dendritic arbors (Gobel, 1975; Gobel et al., 1980; Maxwell et al., 2007). The dendrites of cholinergic interneurons in the dorsal horn of mouse spinal cord have been found to have a rostral-caudal preferential distribution and are more developed in spinal parasagittal sections in the rat (Mesnage et al., 2011). The stalk cell, with a dorsal-ventral dendritic distribution, has been proposed to be an exclusively excitatory component (Gobel, 1978; Gobel et al., 1980; Todd and McKenzie, 1989). A majority of glutamatergic cells in the laminae I and II are vertical/stalked cells (Gobel, 1978; Grudt and Perl, 2002; Maxwell et al., 2007). Although in our current study the morphology of dPSNs did not directly relate to the neurotransmitter phenotype, the predominant glutamatergic proportion, and the dorsal-ventral preferential dendritic distribution 
indicates that this subpopulation of dPSNs may be relatively homogenous. Their dendritic morphology suggests their functions as an integrated and relay unit of dorsal sensory afferent input and ventral brain stem-spinal output. As in Maxwell et al. (2007), although the neurons in our study displayed a predominant morphology, there were other morphologies that may reflect some subtle functional difference in dPSNs.

\section{Limitations of the study}

Although the G-rabies allowed us to visualize Golgi-like dendritic morphology of dPSNs, some limitations exist. For example, the number of GFP-labeled neurons using this method was relatively small representing only a subpopulation of dPSNs. The mechanism by which the G-rabies virus only labels a small number of neurons is not clear. One possible explanation is that the rabies viral infection requires a specific receptor, i.e. neurotrophin receptor (p75NTR) (Sissoeff et al., 2005), and that not all dPSNs express such a receptor. Another explanation is that we only injected a very small amount of virus into the L2 spinal gray matter, which labeled only a small fraction of dPSNs in the T7-9 cord segments that projected to this level. However, such small labeling turned out to be idea for the 3-D reconstruction of dendritic morphology of single dPSNs. For reconstruction, cells with extensively truncated dendritic trees were excluded but it is likely that some long dendritic branches were lost as a consequence of the slice preparation. Future efforts should involve transgenic animal models tagging with a marker for a specific neurotransmitter and apply tissue transparency technology to address these issues (Chung et al., 2013; Collo et al., 2014).

\section{Conclusion}


In summary, we characterized patterns of dendritic organization of dPSNs, an important component of intraspinal network, and investigated the plasticity of the dPSN dendritic arbor after SCI through a monosynaptic transneuronal tracing technique. We demonstrated that DPSNs have a predominant neurotransmitter phenotype and morphological pattern which may be closely related to their function. The dendritic changes occurred in the acute phase providing an early time window for therapeutic interventions to prevent dendritic atrophy as well as to stimulate regenerative responses. Our findings also suggest that dPSNs are particularly sensitive to GDNF during the first week of injury. Several critical questions, however, remain. These include: 1) How do the dPSNs relay the supraspinal commands or integrate sensory afferent signals? 2) How does the plasticity of dPSNs contribute to the functional recovery after SCI? 3) How can a potential therapy, such as the use of GDNF, be optimized to protect dPSNs from injuryinduced cell death and maximize and sustain a regenerative response? 4) How could a potential therapy, such as the use of GDNF, be extended to induce dPSN plasticity in the chronic SCI?

\section{Acknowledgement}

This work was supported in part by Merit Review Award I01 BX002356 from the U.S. Department of Veterans Affairs, NIH NS050243, NS059622, NS073636, DOD CDMRP W81XWH-12-1-0562, Craig H Neilsen Foundation 296749, Indiana Spinal Cord and Brain Injury Research Foundation, Mari Hulman George Endowment Funds, and The 111 Project (B14036), P.R. China. 


\section{Author Disclosure Statement}

No competing financial interests exist.

\section{Supplementary material}

No supplementary material is included.

\section{References}

Airaksinen, M.S., Titievsky, A., Saarma, M., 1999. GDNF family neurotrophic factor signaling: four masters, one servant? Molecular and cellular neurosciences 13, 313325.

Alstermark, B., Isa, T., 2002. Premotoneuronal and direct corticomotoneuronal control in the cat and macaque monkey. Advances in experimental medicine and biology 508, 281-297.

Alstermark, B., Isa, T., Pettersson, L.G., Sasaki, S., 2007. The C3-C4 propriospinal system in the cat and monkey: a spinal pre-motoneuronal centre for voluntary motor control. Acta physiologica 189, 123-140.

Alstermark, B., Lundberg, A., Sasaki, S., 1984. Integration in descending motor pathways controlling the forelimb in the cat. 12. Interneurones which may mediate descending feed-forward inhibition and feed-back inhibition from the forelimb to C3-C4 propriospinal neurones. Experimental brain research 56, 308-322.

Alvarez, V.A., Sabatini, B.L., 2007. Anatomical and physiological plasticity of dendritic spines. Annual review of neuroscience 30, 79-97. 
Ballion, B., Morin, D., Viala, D., 2001. Forelimb locomotor generators and quadrupedal locomotion in the neonatal rat. The European journal of neuroscience 14, 1727-1738.

Barati, S., Hurtado, P.R., Zhang, S.H., Tinsley, R., Ferguson, I.A., Rush, R.A., 2006. GDNF gene delivery via the p75(NTR) receptor rescues injured motor neurons. Experimental neurology 202, 179-188.

Barbeau, H., Rossignol, S., 1987. Recovery of locomotion after chronic spinalization in the adult cat. Brain research 412, 84-95.

Bareyre, F.M., Kerschensteiner, M., Raineteau, O., Mettenleiter, T.C., Weinmann, O., Schwab, M.E., 2004. The injured spinal cord spontaneously forms a new intraspinal circuit in adult rats. Nature neuroscience 7, 269-277.

Baumgartner, B.J., Shine, H.D., 1998. Permanent rescue of lesioned neonatal motoneurons and enhanced axonal regeneration by adenovirus-mediated expression of glial cell-line-derived neurotrophic factor. Journal of neuroscience research 54, 766-777.

Berkowitz, A., Yosten, G.L., Ballard, R.M., 2006. Somato-dendritic morphology predicts physiology for neurons that contribute to several kinds of limb movements. Journal of neurophysiology 95, 2821-2831.

Biernaskie, J., Corbett, D., 2001. Enriched rehabilitative training promotes improved forelimb motor function and enhanced dendritic growth after focal ischemic injury. The Journal of neuroscience : the official journal of the Society for Neuroscience 21, $5272-5280$. 
Bregman, B.S., Broude, E., McAtee, M., Kelley, M.S., 1998. Transplants and neurotrophic factors prevent atrophy of mature CNS neurons after spinal cord injury. Experimental neurology 149, 13-27.

Brown, A.G., 1983. Neuronal organization in the dorsal horn of the spinal cord. Acta morphologica Hungarica 31, 87-99.

Callaway, E.M., 2008. Transneuronal circuit tracing with neurotropic viruses. Current opinion in neurobiology 18, 617-623.

Cambray-Deakin, M.A., Burgoyne, R.D., 1992. Intracellular Ca2+ and N-methyl-Daspartate-stimulated neuritogenesis in rat cerebellar granule cell cultures. Brain research. Developmental brain research 66, 25-32.

Chung, K., Wallace, J., Kim, S.Y., Kalyanasundaram, S., Andalman, A.S., Davidson, T.J., Mirzabekov, J.J., Zalocusky, K.A., Mattis, J., Denisin, A.K., Pak, S., Bernstein, H., Ramakrishnan, C., Grosenick, L., Gradinaru, V., Deisseroth, K., 2013. Structural and molecular interrogation of intact biological systems. Nature 497, 332-337.

Ciccolini, F., Collins, T.J., Sudhoelter, J., Lipp, P., Berridge, M.J., Bootman, M.D., 2003. Local and global spontaneous calcium events regulate neurite outgrowth and onset of GABAergic phenotype during neural precursor differentiation. The Journal of neuroscience : the official journal of the Society for Neuroscience 23, 103-111.

Cline, H.T., 2001. Dendritic arbor development and synaptogenesis. Current opinion in neurobiology $11,118-126$.

Collo, G., Cavalleri, L., Spano, P., 2014. Structural plasticity in mesencephalic dopaminergic neurons produced by drugs of abuse: critical role of BDNF and dopamine. Frontiers in pharmacology 5, 259. 
Cote, M.P., Detloff, M.R., Wade, R.E., Jr., Lemay, M.A., Houle, J.D., 2012. Plasticity in ascending long propriospinal and descending supraspinal pathways in chronic cervical spinal cord injured rats. Frontiers in physiology 3, 330.

Coulon, P., Bras, H., Vinay, L., 2011. Characterization of last-order premotor interneurons by transneuronal tracing with rabies virus in the neonatal mouse spinal cord. The Journal of comparative neurology 519, 3470-3487.

Coumans, J.V., Lin, T.T., Dai, H.N., MacArthur, L., McAtee, M., Nash, C., Bregman, B.S., 2001. Axonal regeneration and functional recovery after complete spinal cord transection in rats by delayed treatment with transplants and neurotrophins. The Journal of neuroscience : the official journal of the Society for Neuroscience 21, 9334-9344.

Courtine, G., Song, B., Roy, R.R., Zhong, H., Herrmann, J.E., Ao, Y., Qi, J., Edgerton, V.R., Sofroniew, M.V., 2008. Recovery of supraspinal control of stepping via indirect propriospinal relay connections after spinal cord injury. Nature medicine 14, 69-74.

Cowley, K.C., Zaporozhets, E., Schmidt, B.J., 2008. Propriospinal neurons are sufficient for bulbospinal transmission of the locomotor command signal in the neonatal rat spinal cord. The Journal of physiology 586, 1623-1635.

Delwaide, P.J., Figiel, C., Richelle, C., 1977. Effects of postural changes of the upper limb on reflex transmission in the lower limb. Cervicolumbar reflex interactions in man. Journal of neurology, neurosurgery, and psychiatry 40, 616-621.

Deng, L.X., Deng, P., Ruan, Y., Xu, Z.C., Liu, N.K., Wen, X., Smith, G.M., Xu, X.M., 2013. A novel growth-promoting pathway formed by GDNF-overexpressing 
Schwann cells promotes propriospinal axonal regeneration, synapse formation, and partial recovery of function after spinal cord injury. The Journal of neuroscience : the official journal of the Society for Neuroscience 33, 5655-5667.

Deng, L.X., Walker, C., Xu, X.M., 2014. Schwann cell transplantation and descending propriospinal regeneration after spinal cord injury. Brain research.

Dolbeare, D., Houle, J.D., 2003. Restriction of axonal retraction and promotion of axonal regeneration by chronically injured neurons after intraspinal treatment with glial cell line-derived neurotrophic factor (GDNF). Journal of neurotrauma 20, 1251-1261.

Donnelly, D.J., Popovich, P.G., 2008. Inflammation and its role in neuroprotection, axonal regeneration and functional recovery after spinal cord injury. Experimental neurology 209, 378-388.

Fargo, K.N., Sengelaub, D.R., 2007. Androgenic, but not estrogenic, protection of motoneurons from somal and dendritic atrophy induced by the death of neighboring motoneurons. Developmental neurobiology 67, 1094-1106.

Fenrich, K.K., Rose, P.K., 2009. Spinal interneuron axons spontaneously regenerate after spinal cord injury in the adult feline. The Journal of neuroscience : the official journal of the Society for Neuroscience 29, 12145-12158.

Ferrer, I., Kulisevski, J., Vazquez, J., Gonzalez, G., Pineda, M., 1988. Purkinje cells in degenerative diseases of the cerebellum and its connections: a Golgi study. Clinical neuropathology 7, 22-28.

Fetcho, J.R., 1992. The spinal motor system in early vertebrates and some of its evolutionary changes. Brain, behavior and evolution 40, 82-97. 
Fiala, J.C., Spacek, J., Harris, K.M., 2002. Dendritic spine pathology: cause or consequence of neurological disorders? Brain research. Brain research reviews 39, 29-54.

Filli, L., Engmann, A.K., Zorner, B., Weinmann, O., Moraitis, T., Gullo, M., Kasper, H., Schneider, R., Schwab, M.E., 2014. Bridging the gap: a reticulo-propriospinal detour bypassing an incomplete spinal cord injury. The Journal of neuroscience : the official journal of the Society for Neuroscience 34, 13399-13410.

Flynn, J.R., Graham, B.A., Galea, M.P., Callister, R.J., 2011. The role of propriospinal interneurons in recovery from spinal cord injury. Neuropharmacology 60, 809-822.

Fouad, K., Dietz, V., Schwab, M.E., 2001. Improving axonal growth and functional recovery after experimental spinal cord injury by neutralizing myelin associated inhibitors. Brain research. Brain research reviews 36, 204-212.

Gerasimenko, Y., Musienko, P., Bogacheva, I., Moshonkina, T., Savochin, A., Lavrov, I., Roy, R.R., Edgerton, V.R., 2009. Propriospinal bypass of the serotonergic system that can facilitate stepping. The Journal of neuroscience : the official journal of the Society for Neuroscience 29, 5681-5689.

Gobel, S., 1975. Golgi studies in the substantia gelatinosa neurons in the spinal trigeminal nucleus. The Journal of comparative neurology 162, 397-415.

Gobel, S., 1978. Golgi studies of the neurons in layer II of the dorsal horn of the medulla (trigeminal nucleus caudalis). The Journal of comparative neurology 180, 395-413.

Gobel, S., Falls, W.M., Bennett, G.J., Abdelmoumene, M., Hayashi, H., Humphrey, E., 1980. An EM analysis of the synaptic connections of horseradish peroxidase-filled 
stalked cells and islet cells in the substantia gelatinosa of adult cat spinal cord. The Journal of comparative neurology 194, 781-807.

Grudt, T.J., Perl, E.R., 2002. Correlations between neuronal morphology and electrophysiological features in the rodent superficial dorsal horn. The Journal of physiology 540, 189-207.

Guevremont, L., Renzi, C.G., Norton, J.A., Kowalczewski, J., Saigal, R., Mushahwar, V.K., 2006. Locomotor-related networks in the lumbosacral enlargement of the adult spinal cat: activation through intraspinal microstimulation. IEEE transactions on neural systems and rehabilitation engineering : a publication of the IEEE Engineering in Medicine and Biology Society 14, 266-272.

Halpain, S., Spencer, K., Graber, S., 2005. Dynamics and pathology of dendritic spines. Progress in brain research 147, 29-37.

Henderson, C.E., Phillips, H.S., Pollock, R.A., Davies, A.M., Lemeulle, C., Armanini, M., Simmons, L., Moffet, B., Vandlen, R.A., Simpson, L.C., et al., 1994. GDNF: a potent survival factor for motoneurons present in peripheral nerve and muscle. Science 266, 1062-1064.

Henze, D.A., Cameron, W.E., Barrionuevo, G., 1996. Dendritic morphology and its effects on the amplitude and rise-time of synaptic signals in hippocampal CA3 pyramidal cells. The Journal of comparative neurology 369, 331-344.

Hirai, H., Launey, T., 2000. The regulatory connection between the activity of granule cell NMDA receptors and dendritic differentiation of cerebellar Purkinje cells. The Journal of neuroscience : the official journal of the Society for Neuroscience 20, $5217-5224$. 
Horch, H.W., Sheldon, E., Cutting, C.C., Williams, C.R., Riker, D.M., Peckler, H.R., Sangal, R.B., 2011. Bilateral consequences of chronic unilateral deafferentation in the auditory system of the cricket Gryllus bimaculatus. Developmental neuroscience $33,21-37$.

Iannotti, C., Li, H., Yan, P., Lu, X., Wirthlin, L., Xu, X.M., 2003. Glial cell line-derived neurotrophic factor-enriched bridging transplants promote propriospinal axonal regeneration and enhance myelination after spinal cord injury. Experimental neurology $183,379-393$.

Illert, M., Lundberg, A., Padel, Y., Tanaka, R., 1978. Integration in descending motor pathways controlling the forelimb in the cat. 5. Properties of and monosynaptic excitatory convergence on $\mathrm{C} 3--\mathrm{C} 4$ propriospinal neurones. Experimental brain research 33, 101-130.

Illert, M., Lundberg, A., Tanaka, R., 1977. Integration in descending motor pathways controlling the forelimb in the cat. 3. Convergence on propriospinal neurones transmitting disynaptic excitation from the corticospinal tract and other descending tracts. Experimental brain research 29, 323-346.

Jankowska, E., 1992. Interneuronal relay in spinal pathways from proprioceptors. Progress in neurobiology 38, 335-378.

Juvin, L., Simmers, J., Morin, D., 2005. Propriospinal circuitry underlying interlimb coordination in mammalian quadrupedal locomotion. The Journal of neuroscience : the official journal of the Society for Neuroscience 25, 6025-6035.

Kashiba, H., Senba, E., 1999. Up- and down-regulation of BDNF mRNA in distinct subgroups of rat sensory neurons after axotomy. Neuroreport 10, 3561-3565. 
Kokaia, Z., Airaksinen, M.S., Nanobashvili, A., Larsson, E., Kujamaki, E., Lindvall, O., Saarma, M., 1999. GDNF family ligands and receptors are differentially regulated after brain insults in the rat. The European journal of neuroscience 11, 1202-1216.

Kostyuk, P.G., Vasilenko, D.A., 1978. Propriospinal neurones as a relay system for transmission of cortico-spinal influences. Journal de physiologie 74, 247-250.

Kuhn, A., Aertsen, A., Rotter, S., 2004. Neuronal integration of synaptic input in the fluctuation-driven regime. The Journal of neuroscience : the official journal of the Society for Neuroscience 24, 2345-2356.

Kusuma, A., ten Donkelaar, H.J., 1979. Staining of the dorsal root primary afferent fibers by anterograde movement of horseradish peroxidase and retrograde labelling of motoneurons and preganglionic autonomic cells in the turtle spinal cord. Neuroscience letters 14, 141-146.

Li, L., Wu, W., Lin, L.F., Lei, M., Oppenheim, R.W., Houenou, L.J., 1995. Rescue of adult mouse motoneurons from injury-induced cell death by glial cell line-derived neurotrophic factor. Proceedings of the National Academy of Sciences of the United States of America 92, 9771-9775.

Mahmood, R., Restrepo, C.E., El Manira, A., 2009. Transmitter phenotypes of commissural interneurons in the lamprey spinal cord. Neuroscience 164, 1057-1067.

Markram, H., Toledo-Rodriguez, M., Wang, Y., Gupta, A., Silberberg, G., Wu, C., 2004. Interneurons of the neocortical inhibitory system. Nature reviews. Neuroscience 5, 793-807. 
Maxwell, D.J., Belle, M.D., Cheunsuang, O., Stewart, A., Morris, R., 2007. Morphology of inhibitory and excitatory interneurons in superficial laminae of the rat dorsal horn. The Journal of physiology 584, 521-533.

Mesnage, B., Gaillard, S., Godin, A.G., Rodeau, J.L., Hammer, M., Von Engelhardt, J., Wiseman, P.W., De Koninck, Y., Schlichter, R., Cordero-Erausquin, M., 2011. Morphological and functional characterization of cholinergic interneurons in the dorsal horn of the mouse spinal cord. The Journal of comparative neurology 519, 3139-3158.

Miller, S., Reitsma, D.J., van der Meche, F.G., 1973. Functional organization of long ascending propriospinal pathways linking lumbo-sacral and cervical segments in the cat. Brain research 62, 169-188.

Naumann, T., Hartig, W., Frotscher, M., 2000. Retrograde tracing with Fluoro-Gold: different methods of tracer detection at the ultrastructural level and neurodegenerative changes of back-filled neurons in long-term studies. Journal of neuroscience methods 103, 11-21.

Neet, K.E., Campenot, R.B., 2001. Receptor binding, internalization, and retrograde transport of neurotrophic factors. Cellular and molecular life sciences : CMLS 58, $1021-1035$.

Nieuwenhuys, R., 1964. Comparative Anatomy of Spinal Cord. Progress in brain research 11, 1-57.

Nishimura, Y., Morichika, Y., Isa, T., 2009. A subcortical oscillatory network contributes to recovery of hand dexterity after spinal cord injury. Brain : a journal of neurology $132,709-721$. 
Nyberg-Hansen, R., 1964. The Location and Termination of Tectospinal Fibers in the Cat. Experimental neurology 9, 212-227.

Nyberg-Hansen, R., 1965. Sites and Mode of Termination of Reticulo-Spinal Fibers in the Cat. An Experimental Study with Silver Impregnation Methods. The Journal of comparative neurology 124, 71-99.

Oppenheim, R.W., Houenou, L.J., Johnson, J.E., Lin, L.F., Li, L., Lo, A.C., Newsome, A.L., Prevette, D.M., Wang, S., 1995. Developing motor neurons rescued from programmed and axotomy-induced cell death by GDNF. Nature 373, 344-346.

Pokorny, J., Trojan, S., 1983. Chronic changes in the receptive field of the pyramidal cells of the rat hippocampus after intermittent postnatal hypoxia. Physiologia Bohemoslovaca 32, 393-402.

Pokorny, J., Trojan, S., Fischer, J., 1982. Changes in the structure of the rat hippocampus after prolonged postnatal hypoxia. Physiologia Bohemoslovaca 31, 193-202.

Ritz, L.A., Greenspan, J.D., 1985. Morphological features of lamina V neurons receiving nociceptive input in cat sacrocaudal spinal cord. The Journal of comparative neurology 238, 440-452.

Rosenzweig, E.S., Brock, J.H., Culbertson, M.D., Lu, P., Moseanko, R., Edgerton, V.R., Havton, L.A., Tuszynski, M.H., 2009. Extensive spinal decussation and bilateral termination of cervical corticospinal projections in rhesus monkeys. The Journal of comparative neurology 513, 151-163.

Rosenzweig, E.S., Courtine, G., Jindrich, D.L., Brock, J.H., Ferguson, A.R., Strand, S.C., Nout, Y.S., Roy, R.R., Miller, D.M., Beattie, M.S., Havton, L.A., Bresnahan, J.C., Edgerton, V.R., Tuszynski, M.H., 2010. Extensive spontaneous plasticity of 
corticospinal projections after primate spinal cord injury. Nature neuroscience 13, 1505-1510.

Ruan, Y.W., Zou, B., Fan, Y., Li, Y., Lin, N., Zeng, Y.S., Gao, T.M., Yao, Z., Xu, Z.C., 2006. Dendritic plasticity of CA1 pyramidal neurons after transient global ischemia. Neuroscience 140, 191-201.

Scheibel, M.E., Scheibel, A.B., 1969. A structural analysis of spinal interneurons and Renshaw cells. UCLA forum in medical sciences 11, 159-208.

Sengelaub, D.R., Forger, N.G., 2008. The spinal nucleus of the bulbocavernosus: firsts in androgen-dependent neural sex differences. Hormones and behavior 53, 596-612.

Sherrington, C.S., 1885. On Secondary and Tertiary Degenerations in the Spinal Cord of the Dog. The Journal of physiology 6, 177-292 110.

Siebert, J.R., Middelton, F.A., Stelzner, D.J., 2010. Intrinsic response of thoracic propriospinal neurons to axotomy. BMC neuroscience 11, 69.

Sissoeff, L., Mousli, M., England, P., Tuffereau, C., 2005. Stable trimerization of recombinant rabies virus glycoprotein ectodomain is required for interaction with the p75NTR receptor. The Journal of general virology 86, 2543-2552.

Skinner, R.D., Adams, R.J., Remmel, R.S., 1980. Responses of long descending propriospinal neurons to natural and electrical types of stimuli in cat. Brain research $196,387-403$.

Sterling, P., Kuypers, H.G., 1968. Anatomical organization of the brachial spinal cord of the cat. 3. The propriospinal connections. Brain research 7, 419-443. 
Storer, P.D., Dolbeare, D., Houle, J.D., 2003. Treatment of chronically injured spinal cord with neurotrophic factors stimulates betaII-tubulin and GAP-43 expression in rubrospinal tract neurons. Journal of neuroscience research 74, 502-511.

Sunanda, Rao, M.S., Raju, T.R., 1995. Effect of chronic restraint stress on dendritic spines and excrescences of hippocampal CA3 pyramidal neurons--a quantitative study. Brain research 694, 312-317.

Tan, A.M., Waxman, S.G., 2012. Spinal cord injury, dendritic spine remodeling, and spinal memory mechanisms. Experimental neurology 235, 142-151.

Todd, A.J., McKenzie, J., 1989. GABA-immunoreactive neurons in the dorsal horn of the rat spinal cord. Neuroscience 31, 799-806.

Ugolini, G., 2011. Rabies virus as a transneuronal tracer of neuronal connections. Advances in virus research 79, 165-202.

Vavrek, R., Girgis, J., Tetzlaff, W., Hiebert, G.W., Fouad, K., 2006. BDNF promotes connections of corticospinal neurons onto spared descending interneurons in spinal cord injured rats. Brain : a journal of neurology 129, 1534-1545.

Vrieseling, E., Arber, S., 2006. Target-induced transcriptional control of dendritic patterning and connectivity in motor neurons by the ETS gene Pea3. Cell 127, 14391452.

Watabe, K., Ohashi, T., Sakamoto, T., Kawazoe, Y., Takeshima, T., Oyanagi, K., Inoue, K., Eto, Y., Kim, S.U., 2000. Rescue of lesioned adult rat spinal motoneurons by adenoviral gene transfer of glial cell line-derived neurotrophic factor. Journal of neuroscience research 60, 511-519. 
Weible, A.P., Schwarcz, L., Wickersham, I.R., Deblander, L., Wu, H., Callaway, E.M., Seung, H.S., Kentros, C.G., 2010. Transgenic targeting of recombinant rabies virus reveals monosynaptic connectivity of specific neurons. The Journal of neuroscience : the official journal of the Society for Neuroscience 30, 16509-16513.

Wickersham, I.R., Finke, S., Conzelmann, K.K., Callaway, E.M., 2007. Retrograde neuronal tracing with a deletion-mutant rabies virus. Nature methods 4, 47-49.

Xu, X.M., Zhang, S.X., Li, H., Aebischer, P., Bunge, M.B., 1999. Regrowth of axons into the distal spinal cord through a Schwann-cell-seeded mini-channel implanted into hemisected adult rat spinal cord. The European journal of neuroscience 11, 1723-1740.

Yuste, R., Bonhoeffer, T., 2004. Genesis of dendritic spines: insights from ultrastructural and imaging studies. Nature reviews. Neuroscience 5, 24-34.

Zhang, L., Ma, Z., Smith, G.M., Wen, X., Pressman, Y., Wood, P.M., Xu, X.M., 2009. GDNF-enhanced axonal regeneration and myelination following spinal cord injury is mediated by primary effects on neurons. Glia 57, 1178-1191.

Zhou, F.Q., Zhong, J., Snider, W.D., 2003. Extracellular crosstalk: when GDNF meets N-CAM. Cell 113, 814-815.

Zuo, Y., Lin, A., Chang, P., Gan, W.B., 2005. Development of long-term dendritic spine stability in diverse regions of cerebral cortex. Neuron 46, 181-189.

\section{Figure legends}

Figure 1. (A) Schematic diagram of the descending propriospinal tract system (dPST). dPST pathways descending several spinal segments are located in both the ventral and 
ventral lateral funiculi (VF and VLF, respectively). The dPST projects through either contralateral or ipsilateral VF or VLF and innervates motoneuron pools directly or indirectly through interneurons. dPST neurons receive convergent supraspinal innervation, including those from the corticospinal (CST) and rubrospinal (RST) tracts. Descending propriospinal neurons are indicated in green, interneurons in brown and motoneurons in purple. $(\mathrm{B}, \mathrm{C})$ Schematic diagrams of the experimental designs for the dendritic morphology study (B) and the neurotransmitter study (C). The three figures in each panel, from left to right, show propriospinal neurons were first retrogradely infected by a G-mutated rabies virus (green particles) that expressed green fluorescence protein which filled the dendritic compartments of dPST neurons (B) or retrogradely labeled by FluoroGold (FG) (blue particles) (C). Spinal cords then received either a transection injury or a transection + glial cell line-derived neurotrophic factor (GDNF) (red dots) applied to the lesion site to be retrogradely transported to the soma.

Figure 2. Camera lucida reconstructions of three propriospinal neurons (rows A, B, C) with different dendritic patterns as if viewed in the transverse (D), parasagittal (E), and horizontal (F) planes. Row A shows a dPSN that extended its dendritic branches in medial, lateral, ventral and dorsal directions. Row B shows a dPSN that extended its dendritic branches predominantly in medial and lateral directions. Row C shows a dPSN that has more dendritic branches extending in ventral and dorsal directions. Scale bar: $100 \mu \mathrm{m}$.

Figure 3. Percentage of dendritic distribution of dPSNs in four quadrant areas. (A) Schematic drawing of a spinal cord transverse section, light grey area corresponds to lamina VII in which all of the dPSNs in this study were located. A representative neuron 
is indicated at right in lamina VII. (B, C) The area surrounding the soma was separated into four quadrants. We defined these four quadrants as lateral: $320^{\circ} \sim 50^{\circ}$; dorsal: $50^{\circ} \sim 140^{\circ}$; medial: $140^{\circ} \sim 230^{\circ}$; ventral: $230^{\circ} \sim 320^{\circ}$. (D) Comparison of percentage distribution of dendrites among the sham, transected (TX) and TX + GDNF groups. $* p$ $<0.05 \mathrm{TX}+$ GDNF lateral versus sham lateral; $* * p<0.01 \mathrm{TX}$ lateral versus sham lateral; \& $p<0.05$ TX dorsal or TX + GDNF dorsal versus sham dorsal; \#\# $p<0.01$ sham medial versus sham dorsal; \#\#\# $p<0.001$ sham lateral versus sham dorsal; $\$ p<$ 0.05 sham ventral versus sham medial; $\$ \$ \$ p<0.001$ sham ventral versus sham lateral..

Figure 4. Comparison of the dendritic features of the 36 GFP-labeled and fully reconstructed dPSN neurons from sham $(n=15)$, transection injury $(T X, n=10)$ and $T X+$ GDNF treatment groups (n=11). (A) total dendritic length; (B) dendritic interval length; (C) terminal dendritic length; (D) number of dendritic end branches/cell; (E) number of total dendritic branches; (F) number of dendritic nodes; (G) number of terminal dendritic branches; and $(\mathrm{H})$ maximal order of dendritic branches. *: $p<0.05$; **: $p<0.01$, Compared to sham group. Bar heights represent means \pm SD.

Figure 5. Morphological plasticity of dendritic spine-like structures of dPSNs after axotomy injury treated with or without GDNF. (A) Schematic drawings and representative images of the five different types of spine-like structures. Comparisons of the number (B), density (C), number by branch order, (D) percentage of types of spinelike structures overall and by the different types across the sham, TX, and TX + GDNF groups. ${ }^{*} p<0.05$ compared with sham group. ${ }^{* *} p<0.01$ compared with sham group. Bar heights represent means $\pm \mathrm{SD}$. 
Figure 6. Co-localizations of retrograde tracer FluoroGold (FG) with neurotransmitter markers in sub-populations of dPSNs. (A-C) The majority of neurons labeled by FG were glutamatergic (white arrow, red glutamate, blue FG), (D-F) a small percentage of neurons labeled by FG were ChAT-positive neurons (white arrow, red ChAT, blue FG). (G-I) a small percentage of neurons labeled by FG were GABAergic neurons (white arrow, green GABA, blue FG). (J-L) a small percentage of neurons labeled by FG were glycinergic neurons (white arrow, green glycine, blue FG). Scale bar: $10 \mu \mathrm{m}$.

Figure 7. (A) Percentage distribution of subpopulations of four different neurotransmitters in the sham group. The majority of FG-labeled dPSNs are glutamatergic neurons. $* * * p<0.001$ compared with glutamatergic neurons. (B) Total number of FG-labeled neurons in the $\mathrm{T} 7$ and $\mathrm{T} 9$ spinal segments in sham animals and after spinal transection (TX) with or without GDNF treatment. The number of FG-labeled cells is decreased in T9 spinal cord after transection injury regardless of treatment with GDNF. *** $p<0.001$ compared with sham group. 


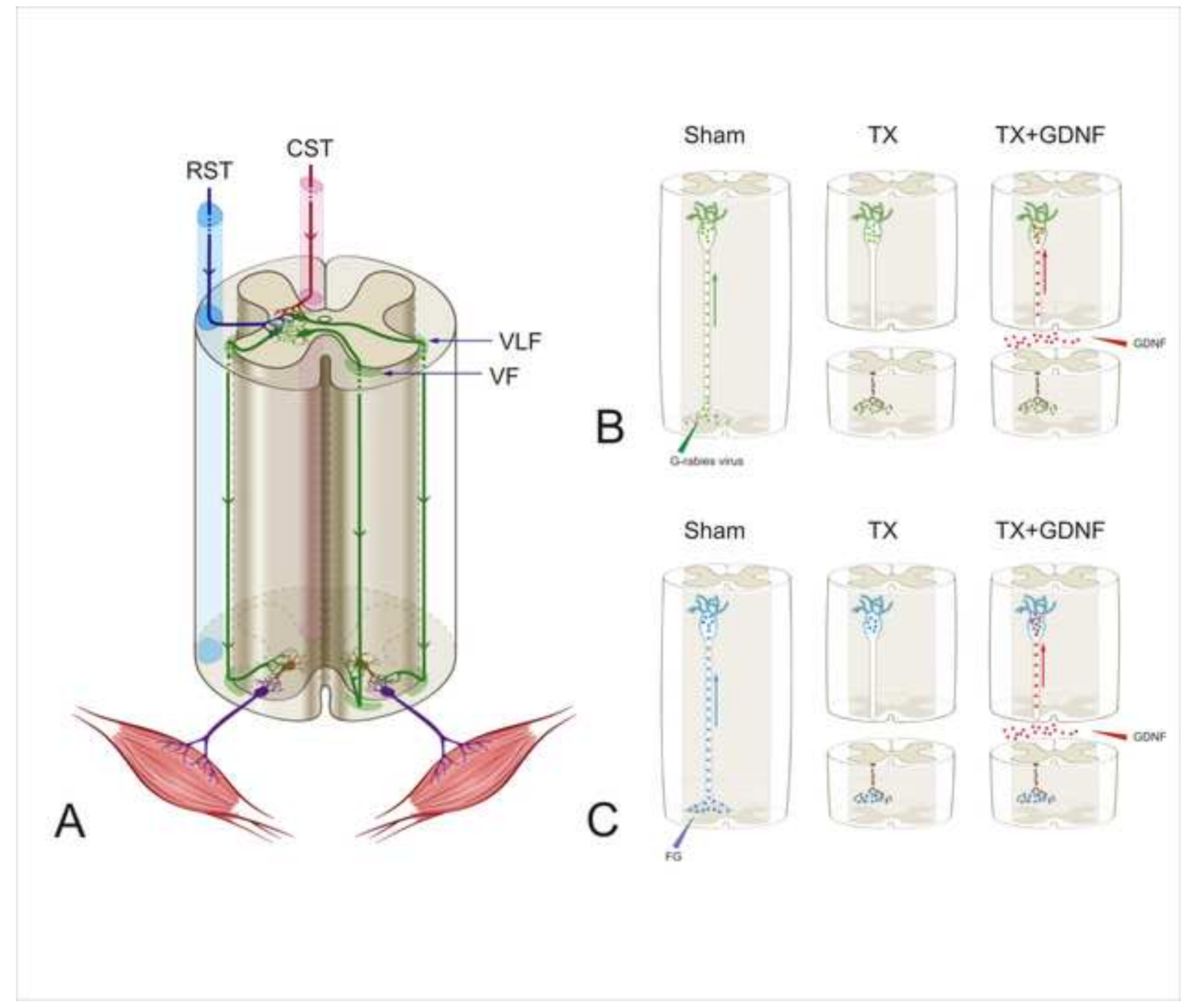



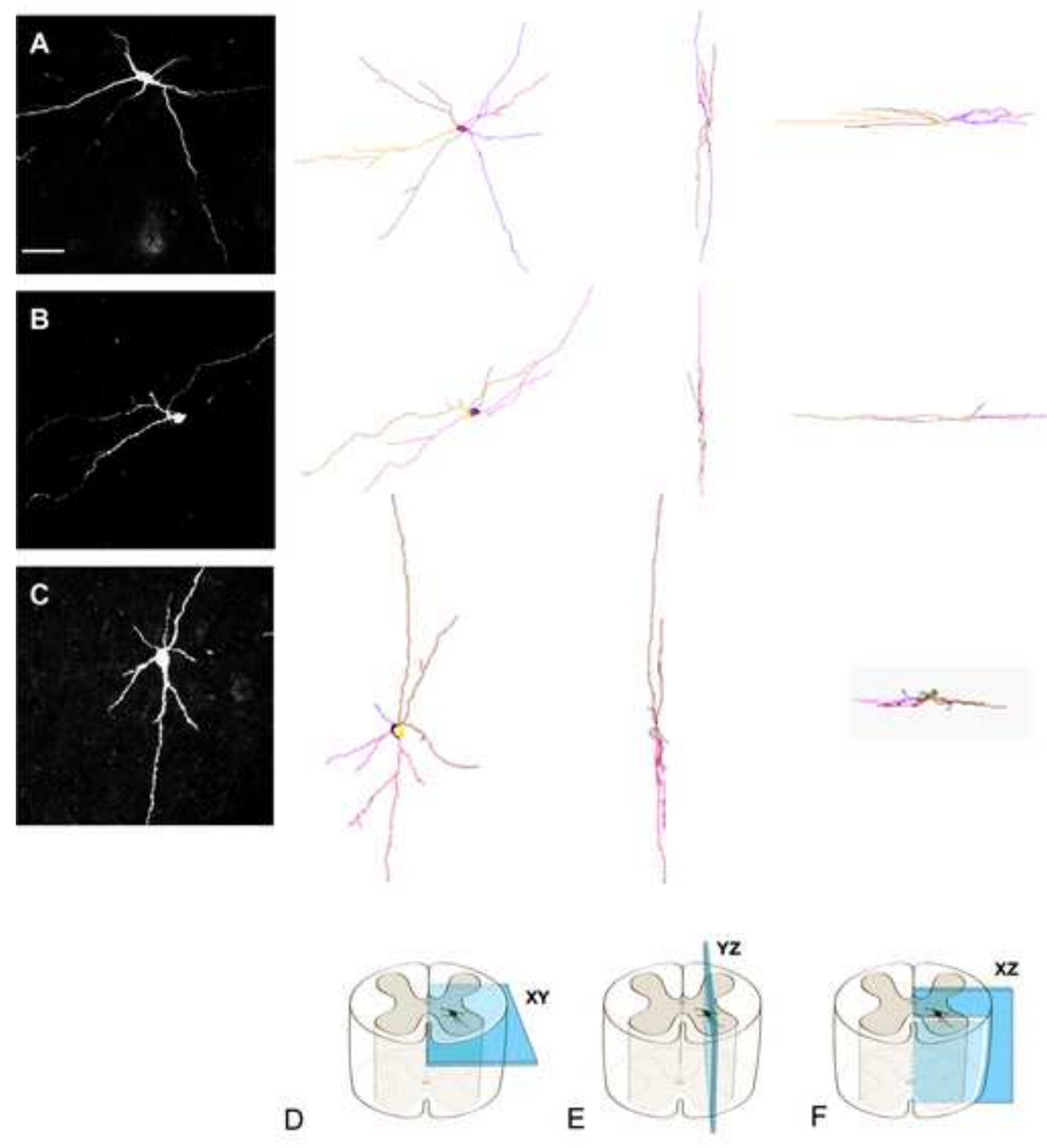

Figure 2

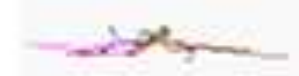

F

D

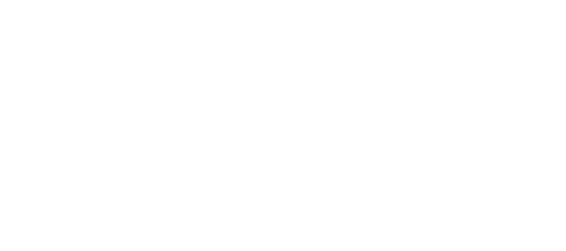




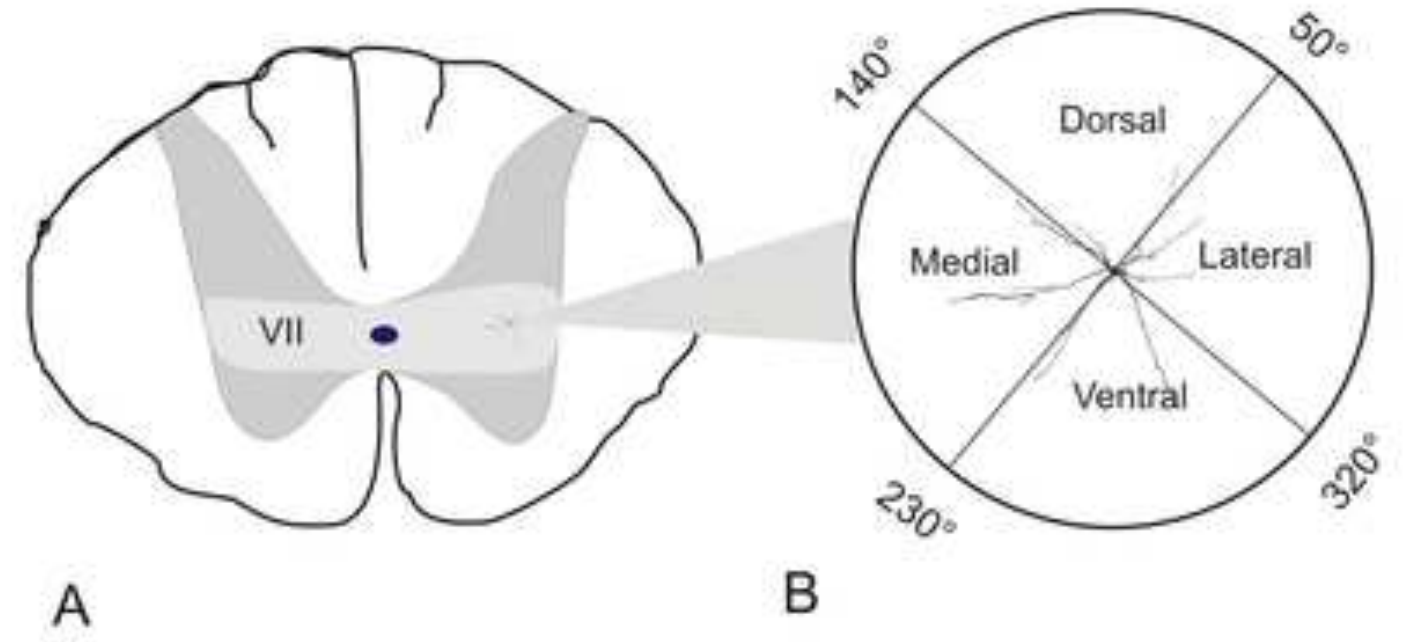

A
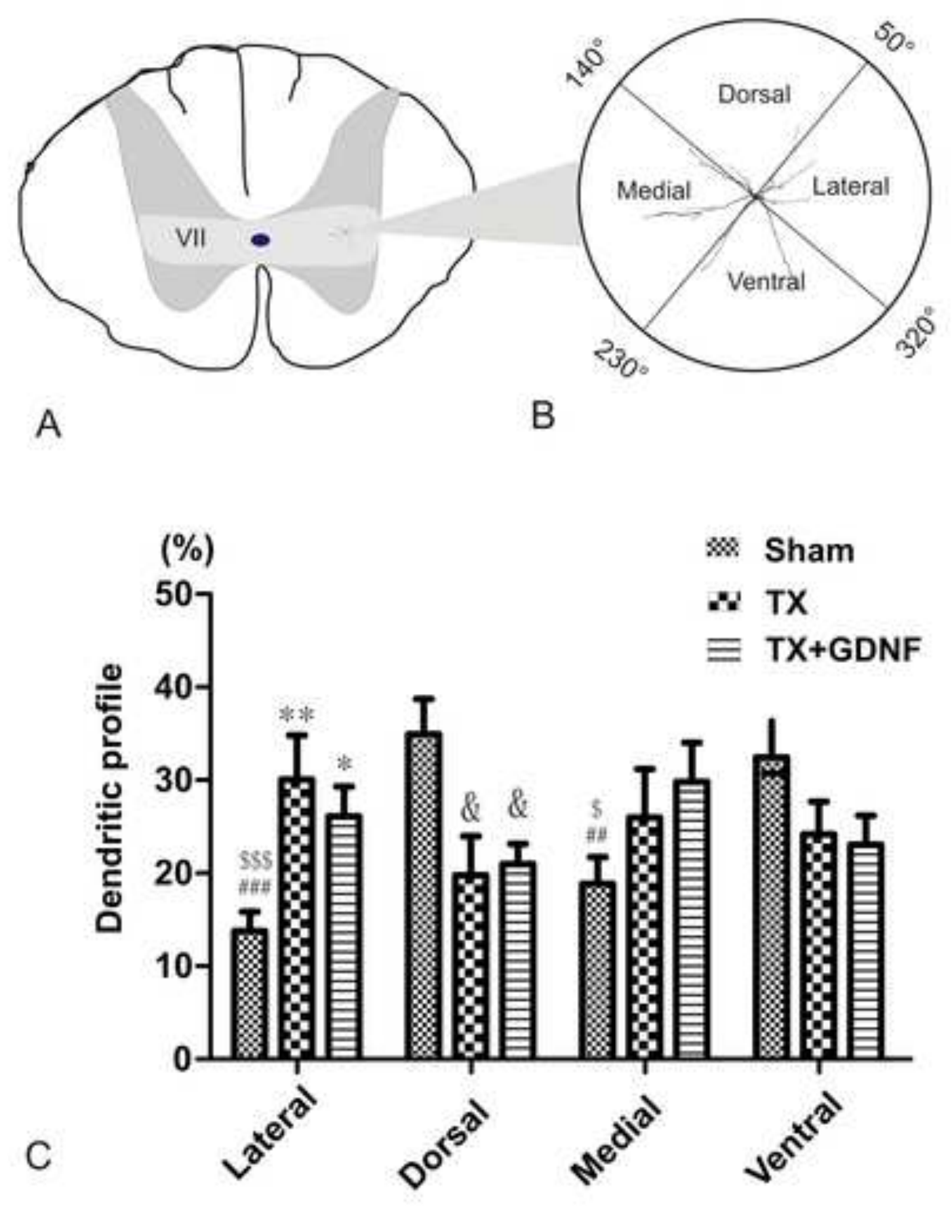

Figure 3
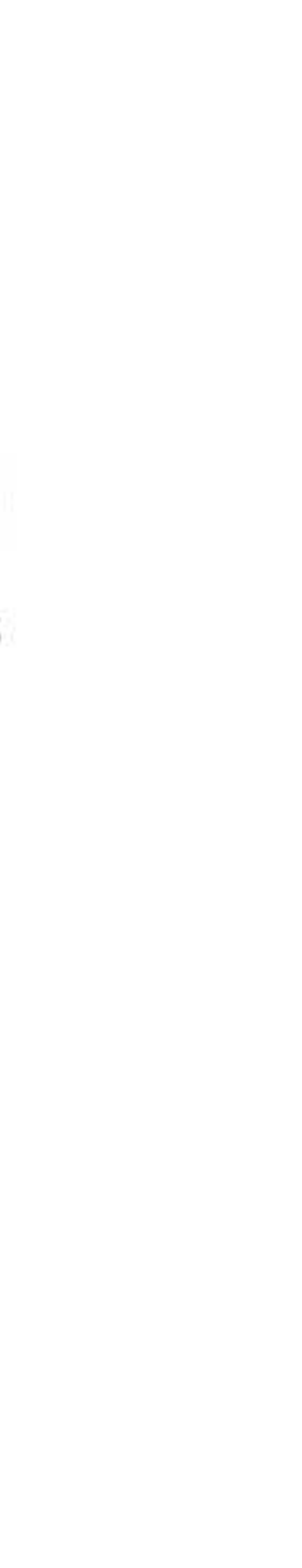

B 

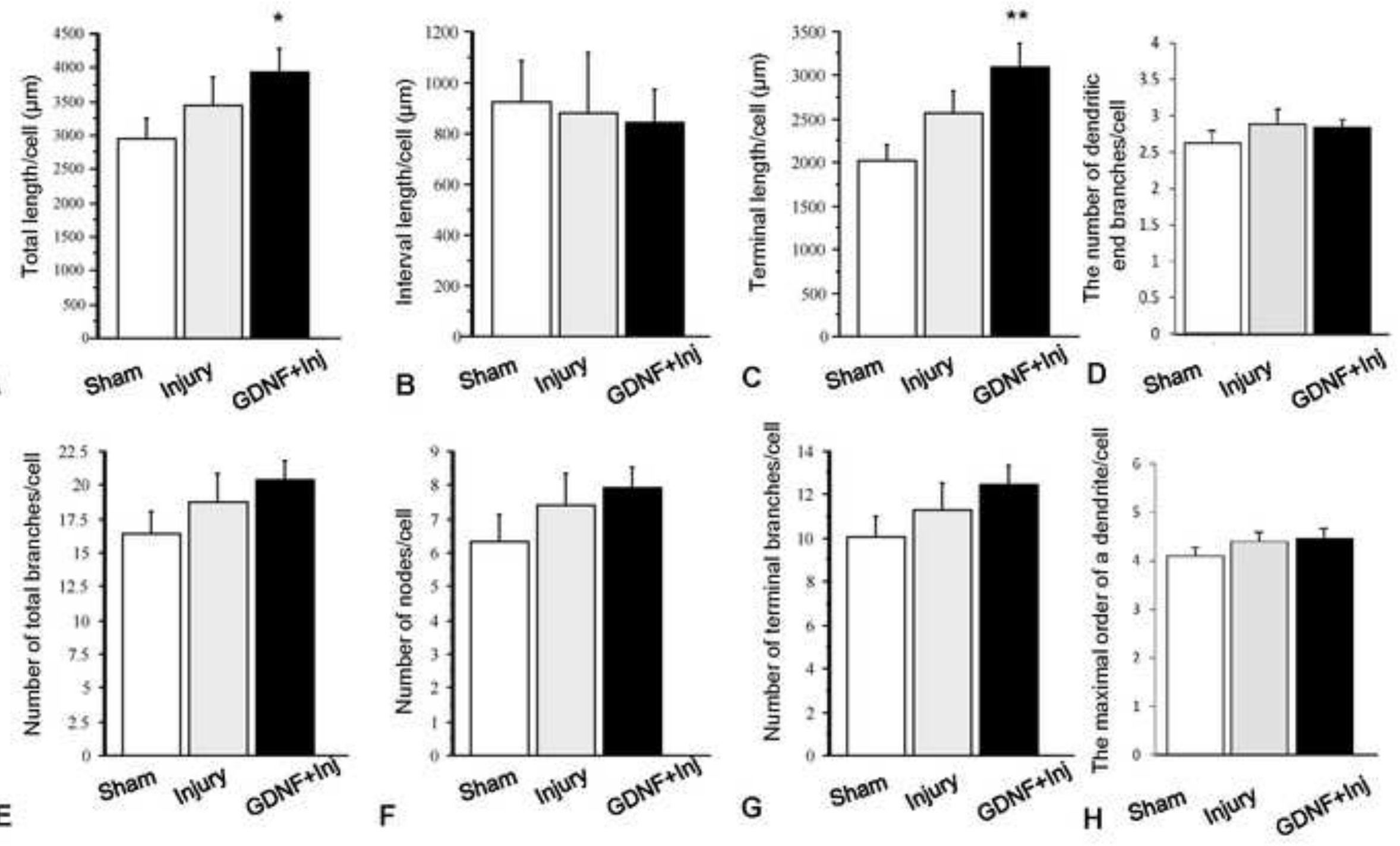

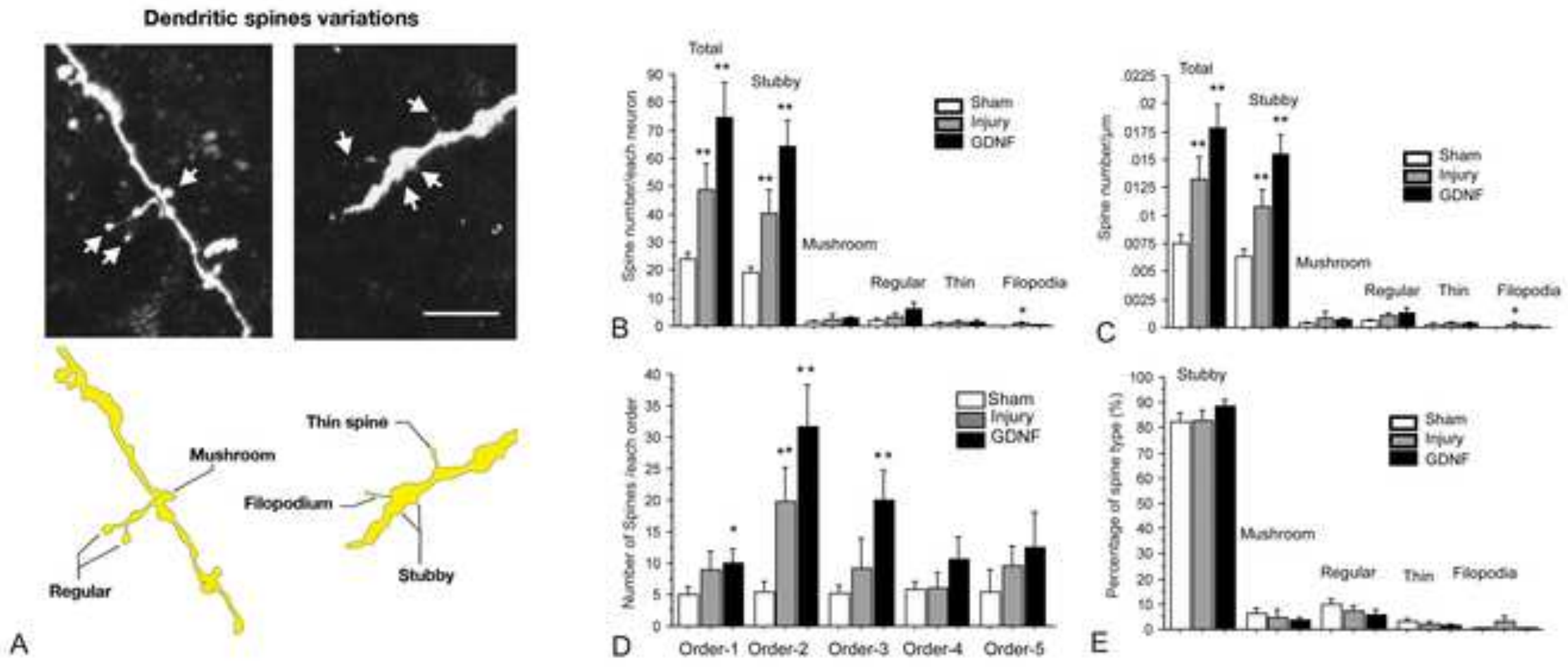


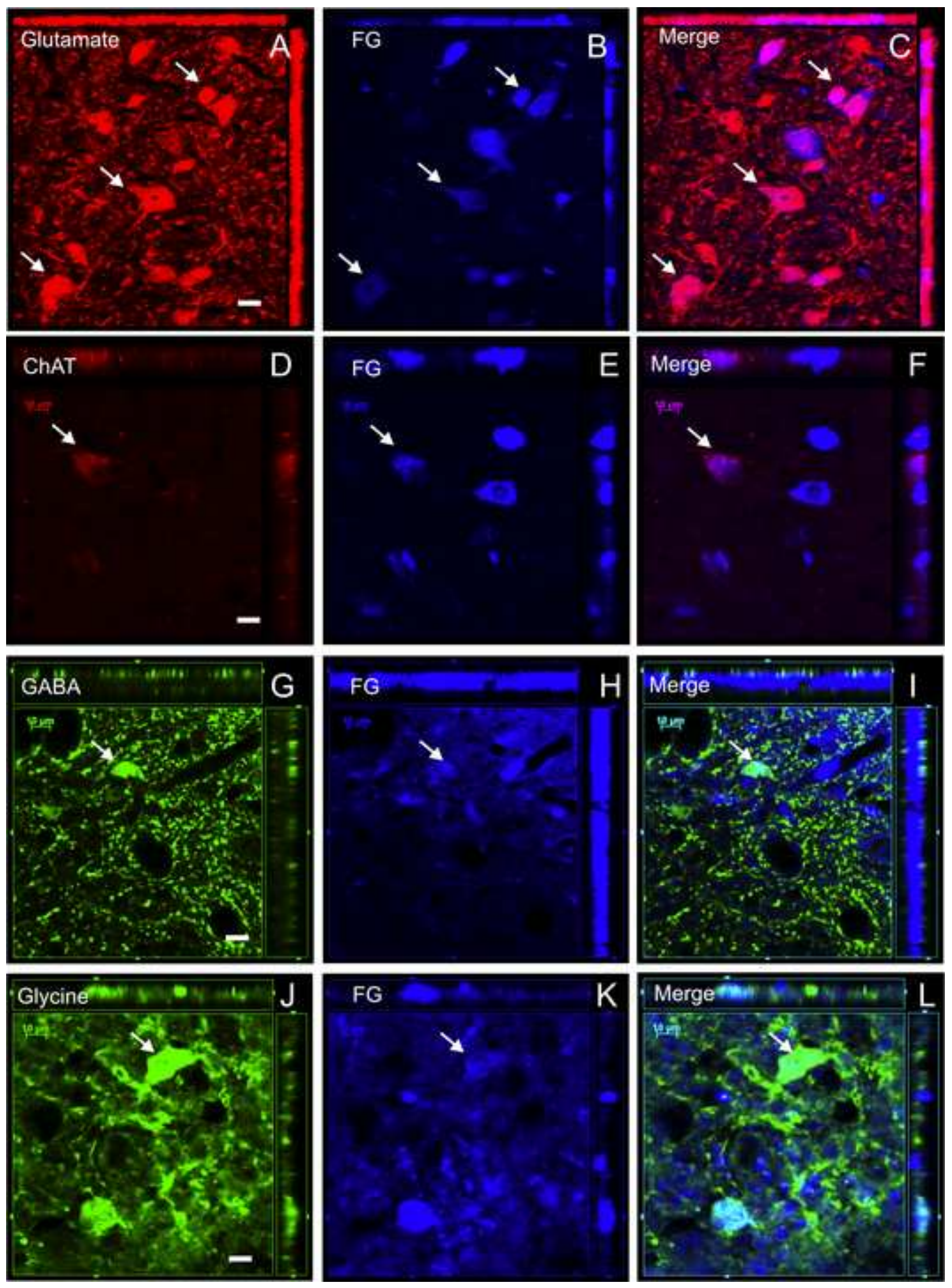




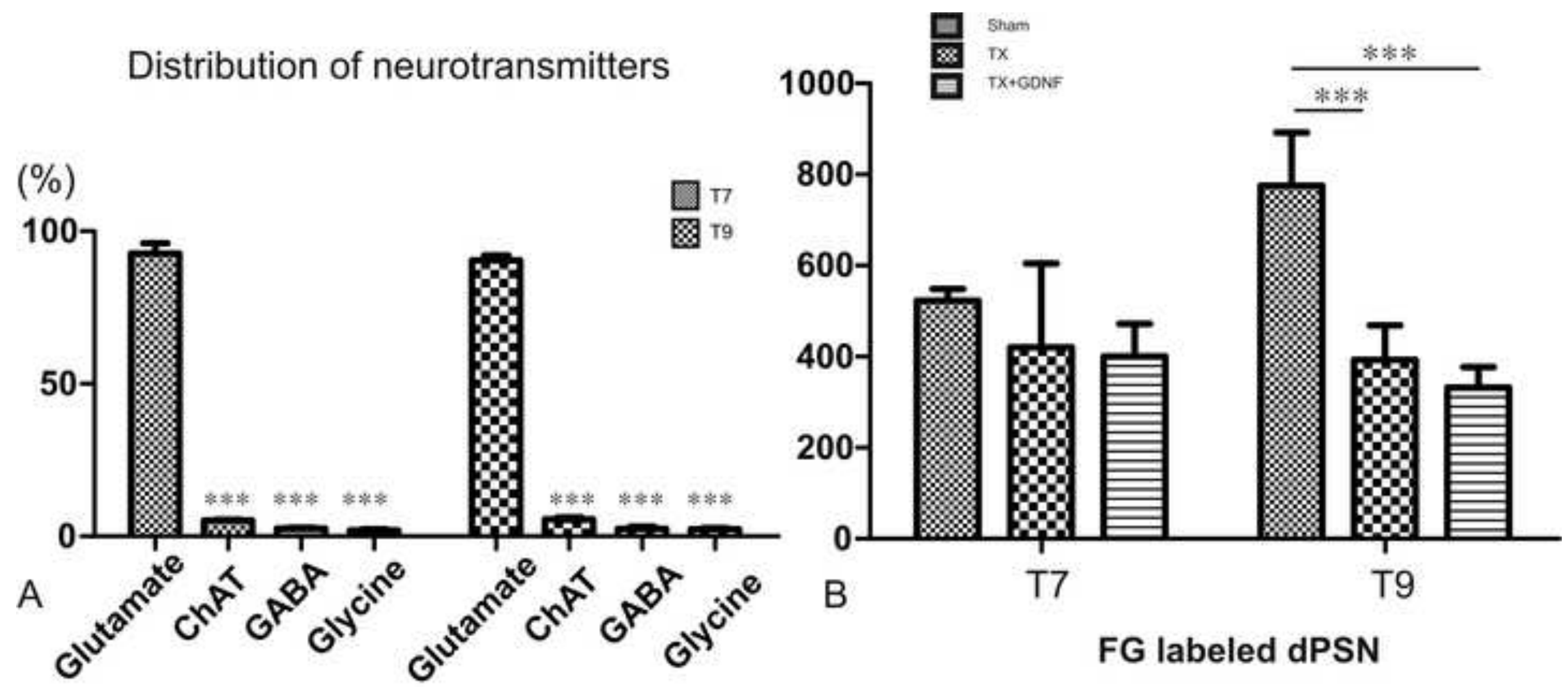

